\title{
Identification of functional TFAP2A and SP1 binding sites in new TFAP2A-modulated genes
}

Francesca Orso ${ }^{+1,4}$, Davide Coràt2,4,5, Benedetta Ubezio 1,6, Paolo Provero³, Michele Caselle ${ }^{+2,4}$ and Daniela Taverna*+1,4

\begin{abstract}
Background: Different approaches have been developed to dissect the interplay between transcription factors (TFs) and their cis-acting sequences on DNA in order to identify TF target genes. Here we used a combination of computational and experimental approaches to identify novel direct targets of TFAP2A, a key TF for a variety of physiological and pathological cellular processes. Gene expression profiles of HeLa cells either silenced for TFAP2A by RNA interference or not were previously compared and a set of differentially expressed genes was revealed.
\end{abstract}

Results: The regulatory regions of 494 TFAP2A-modulated genes were analyzed for the presence of TFAP2A binding sites, employing the canonical TFAP2A Positional Weight Matrix (PWM) reported in Jaspar http://jaspar.genereg.net/. 264 genes containing at least 2 high score TFAP2A binding sites were identified, showing a central role in "Cellular Movement" and "Cellular Development". In an attempt to identify TFs that could cooperate with TFAP2A, a statistically significant enrichment for SP1 binding sites was found for TFAP2A-activated but not repressed genes. The direct binding of TFAP2A or SP1 to a random subset of TFAP2A-modulated genes was demonstrated by Chromatin ImmunoPrecipitation (ChIP) assay and the TFAP2A-driven regulation of DCBLD2/ESDN/CLCP1 gene studied in details.

Conclusions: We proved that our computational approaches applied to microarray selected genes are valid tools to identify functional TF binding sites in gene regulatory regions as confirmed by experimental validations. In addition, we demonstrated a fine-tuned regulation of DCBLD2/ESDN transcription by TFAP2A.

\section{Background}

The coordination of various complex biological functions as well as the response to environmental and developmental stimuli are governed by biochemical processes that regulate gene activity. Transcription is the initial step of gene expression and it involves a multitude of transcription factors (TFs), their corresponding cis-acting elements on DNA, additional co-factors and the influence of chromatin structure [1]. Functional TF binding sites (TFBSs) can be identified in the genome by computational approaches or experimentally by Chromatin ImmunoPrecipitation and hybridization on a genomic microarray (ChIP on Chip) [2] or by high-throughput selection procedures (SELEX) in which pools of random DNA sequences are mixed with a TF and those that are preferentially bound are recovered and sequenced $[3,4]$.

\footnotetext{
*Correspondence: daniela.taverna@unito.it

${ }^{1}$ Molecular Biotechnology Center (MBC) and Department of Oncological

Sciences, University of Torino, Via Nizza, 52, 10126 Torino, Italy

+ Contributed equally

Full list of author information is available at the end of the article
}

However, an alternative and very promising approach consists in combining in silico TFBS predictions in the gene promoter regions and microarray analyses, comparing gene expression of cells in which a TF is either overexpressed or deleted [5-7]. Indeed, the analysis of regulatory sequences of putative co-regulated genes might be useful in identifying common cis-regulatory elements recognized by specific TFs [5]. The microarray assays help to narrow down the number of genes to be analyzed, focusing on those more likely to be regulated by the same TFs, thus reducing the false positive and negative rates.

The Activator Protein-2 (TFAP2) family of transcription factors includes five different yet closely related proteins known as TFAP2A, TFAP2B, TFAP2C, TFAP2D and TFAP2E [8-12] encoded by different genes. TFAP2 can positively or negatively regulate the promoter activity of many pivotal genes involved in physiological or pathological processes such as development, cell growth, differentiation, apoptosis and tumorigenesis [12]. Among the positively regulated genes are: CDKN1A, TGFA, estrogen receptor, keratinocyte-specific genes, KIT, HIV 
KTF1, HTLVI, type IV collagenase, SV40 enhancer region, human metallothionein gene IIa, ERBB2, IGFB5, dopamine beta-hydroxylase. Examples of repressed genes are: $M C A M, C E B P A$ and $M Y C$ [12]. The crucial role of the TFAP2 genes in regulating fundamental biological processes is highlighted by the embryonic lethality of the genetically modified Tcfap2a or Tcfap2b or Tcfap 2 g mice $[12,13]$.

Every TFAP2 protein possesses a unique, highly conserved helix-span-helix dimerization motif at the C-terminal half of the protein, a central basic region and a less conserved proline- and glutamine-rich domain at the amino terminus [14]. The helix-span-helix motif and the basic region mediate DNA binding and dimerization [15] while the proline- and glutamine rich region is responsible for transcriptional transactivation. The TFAP2 proteins are able to form hetero- as well as homo-dimers and bind to GC-rich DNA sequences within regulatory regions of their target genes, mediating both activation and repression of gene transcription [12]. Functional TFAP2 binding sites, such as 5'-GCCN3GGC-3' or 5'GCCN4GGC-3' or 5'-GCCN3/4GGG-3' have been identified [16]. However other well characterized binding sites, such as 5'-CCCCAGGC-3' [17] or others [18], which differ considerably from the previous sequences, have also been found, indicating that TFAP2 binding sites may represent promiscuous GC-rich elements varying considerably in binding affinity. This makes the computational identification of TFAP2 binding sites not a trivial process. A Positional Frequency Matrix (PFM) obtained by multiple alignment algorithms, which leads to nucleotide scores indexed by letters and positions is often used to localize degenerated cis-regulatory elements [19]. In addition, given that TFAP2 isoforms are very similar in their DNA binding domains, a specific sequence preference between different TFAP2 proteins has not been found, as demonstrated by an in vitro binding site selection with recombinant TFAP2A and TFAP2C proteins [20].

Several molecular mechanisms control the TFAP2 protein activity and physical interactions with other proteins play an important role. Among the most important known TFAP2 interacting proteins, we can list DNA binding factors such as YY1 [21]; YB1 [22]; TP53 [23]; SP1 [24]; MYC [25]; PAX6 [26]; RB1 [25]; CUX1 [27]; viral proteins such as SV40 large $\mathrm{T}$ antigen, 1 human $\mathrm{T}$ cell leukemia virus type 1 [28] and adenovirus E1A protein [29] as well as non-DNA-binding factors such as WWOX [30]; GAS41 [31]; PARP1 [32]; APC [33]; CREB [34]; CITED2 and 4 [35]; PC4 [36]; DEK [37] and YAP [38].

We previously performed whole-genome microarray analysis for HeLa cells either silenced for TFAP2A by RNA interference or not and identified a set of differen- tially expressed genes [39]. The regulatory regions (-900/ +100 , considering the TSS as +1 ) of the genes that unambiguously mapped to known ENSEMBL IDs were analyzed for the presence of TFAP2A binding sites, employing the canonical Positional Weight Matrix (PWM) reported in Jaspar http://jaspar.genereg.net/. 264 genes containing at least 2 high score TFAP2A binding sites were identified, several of which could be validated by Chromatin ImmunoPrecipitation (ChIP) assays. Additionally, a detailed analysis of the TFAP2A-driven regulation of the Discoidin, CUB and LCCL domain containing 2/Endothelial and Smooth muscle Derived Neuropilin like/CUB, LCCL-homology, coagulation factor V/VIII homology domains (DCBLD2/ESDN/CLCP1) gene was performed. Finally we searched for TFs that might cooperate with TFAP2A in the transcriptional regulation of genes containing at least 2 high score TFAP2A binding sites and found SP1 as a potential candidate for TFAP2A activated genes.

\section{Results \\ Identification of TFAP2A binding sites in newly identified TFAP2A-modulated genes}

In order to define TFAP2A binding sites in newly identified TFAP2A-modulated genes [39] we first assembled a dataset of core promoter regions $(-900 /+100$, considering the TSS as +1 ) for all known human protein-coding genes (21316) using the ENSEMBL database and searched for TFAP2A binding sites employing the canonical TFAP2A Positional Weight Matrix (PWM) MA0003 (Figure 1) reported in the Jaspar database. Affinity scores were assigned using standard log-likelihood ratios [40] and a binding site defined as an oligonucleotide with log-likelihood ratio higher than $66 \%$ of the maximum score possibly associated to the PWM. After ranking the binding sites by score, we used various thresholds (top-scoring $10 \%, 20 \%$ and $30 \%$ sites) to classify the genes containing at least one or two high score TFAP2A binding sites (Table 1). In the following we will mostly consider the top-scoring $20 \%$ binding sites. We then focused on the set of the differentially expressed genes identified by microarray analysis [39], in which gene expression profiles of HeLa cells, either silenced for TFAP2A by RNA interference or not were compared considering a Fold Change $(\mathrm{FC})> \pm 1.5$ and a $\mathrm{p}$ value $\left(\mathrm{p}_{\mathrm{v}}\right)<0.01$. For each of them the longest available transcript was chosen (see Additional file 1). Significant enrichment for TFAP2A binding sites was found in the regulatory regions of these genes compared with genome-wide abundance as calculated using an exact Fisher test, as shown in Table 1. In the whole genome the genes containing at least one or two high score TFAP2A binding sites were respectively 12686 and 8636 whereas, among TFAP2A-regulated genes, 363 out of 494 genes (ENSEMBL) contained at 
Table 1: Identification of TFAP2A binding sites in the core promoter of candidate TFAP2A-modulated genes.

\begin{tabular}{|c|c|c|c|c|}
\hline $\begin{array}{l}\text { Minimum number of } \\
\text { binding sites per gene }\end{array}$ & $\begin{array}{l}\text { TFA2A binding site } \\
\text { score threshold }\end{array}$ & Genome-wide & TFAP2A-regulated genes & p (Fisher test) \\
\hline \multirow[t]{4}{*}{1} & All sites & 19402 & 468 & \\
\hline & best $30 \%(\geq 11.02)$ & 14710 & 401 & 7.03E-08 \\
\hline & best $20 \%(\geq 11.44)$ & 12686 & 363 & $4.56 \mathrm{E}-09$ \\
\hline & best $10 \%(\geq 12.14)$ & 9416 & 283 & $1.02 \mathrm{E}-07$ \\
\hline \multirow[t]{4}{*}{2} & All sites & 17540 & 447 & \\
\hline & best $30 \%(\geq 11.02)$ & 10959 & 322 & $1.03 \mathrm{E}-05$ \\
\hline & best $20 \%(\geq 11.44)$ & 8636 & 264 & $1.53 \mathrm{E}-05$ \\
\hline & best $10 \%(\geq 12.14)$ & 4955 & 155 & $2.0 \mathrm{E}-03$ \\
\hline
\end{tabular}

least one high score TFAP2A binding site while 264 out of 494 (157 down- and 107 up-regulated) genes (ENSEMBL) contained a minimum of two sites indicating an enrichment for TFAP2A binding sites in the TFAP2A-regulated genes $\left(\mathrm{p}_{\mathrm{v}}=1.5 \mathrm{E}-05\right)$, see Table 1 . The results for different thresholds (top $10 \%$ and $30 \%$ ) were similarly significant and shown in Table 1. We ranked the genes according to the number of TFAP2A binding sites present in their core promoter regions (Table 2) and found that the majority of the genes contained one or two TFAP2A binding site/s. It's important to underline that already reported TFAP2A target genes were identified in our analysis (see Additional file 1).

\section{Functional classes enrichment for predicted TFAP2A target genes}

To identify the functional pathways in which the potential TFAP2A targets could be involved Gene Ontology (GO) and network analyses were performed for the 264 TFAP2A-modulated genes containing at least two TFAP2A high score binding sites using the Ingenuity Pathway Analysis Systems. Two high score molecular networks were identified and in Figure $2 \mathrm{~A}$ and $2 \mathrm{~B}$ we show a selection of these genes and their connections with TFAP2A. The first network associated with Cellular Movement (Figure 2A, score 38) and included 26 genes, i.e. SLIT2 (slit homolog 2 -Drosophila); PDGFA (plateletderived growth factor alpha polypeptide); $R A C 1$ and
RAC2 (ras-related C3 botulinum toxin substrate 1 and 2, rho family, small GTP binding protein Rac1 and Rac2); $D C B L D 2 / E S D N$ (discoidin, CUB and LCCL domain containing 2/Endothelial and Smooth muscle cell Derived Neuropin-like molecule); ACTA2 (actin, alpha 2, smooth muscle, aorta). The second network associated with Cellular Development (Figure 2B, score 38) and included 24 genes, i.e. PPARG (peroxisome proliferator-activated receptor gamma); $M A P K 1$ (mitogen-activated protein kinase 1); CXCL1 (chemokine, C-X-C motif, ligand 1 melanoma growth stimulating activity, alpha); ADAMTS1 (metallopeptidase with thrombospondin type 1 motif, 1); AREG (amphiregulin); IL11 (interleukin 11).

Functional validation of potential TFAP2A-regulated genes Potential TFAP2A binding was tested for 13 candidate target genes containing at least one or two best $20 \%$ TFAP2A binding sites by Chromatin Immuno Precipitation (ChIP) assay (Figures 3 and 6): ADAMTS1 (ADAM metallopeptidase with thrombospondin type 1 motif, 1 ); CASP9 (caspase 9); CD59 (CD59 molecule, complement regulatory protein); CXCL1 (chemokine ligand 1, melanoma growth stimulating activity alpha); EREG (Epiregulin); $D C B L D 2 / E S D N$ (endothelial and smooth muscle cell derived neuropiline like molecule); FASTK (Fas-activated serine/threonine kinase); GLO1 (glyoxalase I); KRT16 (keratin 16); KRT17 (keratin 17); PPARG (peroxisome proliferator activated receptor gamma); SLIT2 (slit 
Table 2: Distribution of genes containing TFAP2A binding sites.

\begin{tabular}{|c|c|c|c|c|}
\hline \multirow[b]{3}{*}{ Minimum number of binding sites per gene best $20 \%(\geq 11.44)$} & \multicolumn{4}{|c|}{ Genes } \\
\hline & \multicolumn{2}{|c|}{ Genome-wide } & \multicolumn{2}{|c|}{ TFAP2A-regulated } \\
\hline & $\mathbf{n}^{\circ}$ & $\%$ & $\mathbf{n}^{\circ}$ & $\%$ \\
\hline 1 & 12686 & 65.36 & 363 & 77.56 \\
\hline 2 & 8636 & 44.50 & 264 & 56.41 \\
\hline 3 & 5967 & 30.75 & 185 & 39.53 \\
\hline 4 & 4131 & 21.30 & 133 & 28.42 \\
\hline 5 & 2816 & 14.51 & 102 & 21.79 \\
\hline 6 & 1948 & 10.04 & 72 & 15.38 \\
\hline 7 & 1339 & 6.90 & 51 & 10.90 \\
\hline 8 & 920 & 4.74 & 35 & 7.48 \\
\hline 9 & 646 & 3.33 & 22 & 4.70 \\
\hline 10 & 448 & 2.31 & 14 & 2.99 \\
\hline 11 & 297 & 1.53 & 12 & 2.56 \\
\hline 12 & 195 & 1.00 & 7 & 1.50 \\
\hline 13 & 129 & 0.66 & 4 & 0.85 \\
\hline 14 & 85 & 0.44 & 1 & 0.21 \\
\hline 15 & 57 & 0.29 & 0 & 0 \\
\hline 16 & 31 & 0.16 & 0 & 0 \\
\hline 17 & 20 & 0.10 & 0 & 0 \\
\hline 18 & 14 & 0.07 & 0 & 0 \\
\hline 19 & 8 & 0.04 & 0 & 0 \\
\hline 21 & 5 & 0.03 & 0 & 0 \\
\hline 22 & 3 & 0.01 & 0 & 0 \\
\hline
\end{tabular}


Table 2: Distribution of genes containing TFAP2A binding sites. (Continued)

\begin{tabular}{cccccc}
\hline 26 & 2 & 0.01 & 0 & 0 \\
\hline 27 & 1 & 0.01 & 0 & 0 \\
\hline
\end{tabular}

Distribution of genome-wide or TFAP2A-modulated genes based on absolute number of genes (or percentages, \%) containing one or more high score (best 20\%) TFAP2A binding sites in their core promoters.

homolog 2, Drosophila); TGFBI (Transforming Growth Factor B-Induced). The ENSEMBL ID, microarray Fold Change (FC) and TFAP2A binding sequences, scores and positions for each of these genes is shown in Table 3. ChIP analysis was performed on HeLa cells, that endogenously express TFAP2A and as shown in Figure 3 and 6, enrichment for TFAP2A was found on the promoter of each gene compared with negative controls, suggesting in vivo binding and direct regulation of these genes by TFAP2A. Negative controls for ChIP analysis were performed using genes in which low score or no TFAP2A binding sites were identified such as PLCXD2 (pleckstrin homology-like domain family B member 2) or IFI44 (interferon-induced protein 44). In fact, no enrichment for TFAP2A was observed in the promoter of these two genes compared with the negative IgG controls suggesting that genes containing only low score or no TFAP2A binding sites are not direct TFAP2A targets and their TFAP2A-dependent modulation is indirect. ChIP analysis for PPARG and PLCXD2 genes was also performed in HepG2 cells that do not express TFAP2A and no enrichment for TFAP2A was observed for any of the analyzed sequences supporting the significance of the results obtained in HeLa cells (Figure 3 and 6).

\section{The DCBLD2/ESDN/CLCP1 promoter region is directly regulated by TFAP2A}

DCBLD2/ESDN/CLCP1 (discoidin, CUB and LCCL domain containing $2 /$ Endothelial and Smooth muscle cell Derived Neuropin-like molecule/CUB, LCCL-homology, coagulation factor V/VIII homology domains protein) turned out to be the most highly modulated (repressed) gene in our microarray analysis on HeLa cells (FC + 5.7) and to have an important role in cell migration [39]. For these reasons we carried on a detailed computational analysis of the $D C B L D 2 / E S D N$ regulatory region, extended to $(-2185 /+89$ with respect to the TSS), and found high enrichment of GC content and no TATA box around the TSS, features which are common to the core promoters of TFAP2A targets identified with our computational analysis. This sequence was analyzed to position potential TFAP2A binding sites using the canonical TFAP2A Positional Weight Matrix (PWM) as in Jaspar database (see above). Three highly scored TFAP2A binding sites were identified in the region $-360 /+89$. A schematic representation of the $2.185 \mathrm{~Kb} D C B L D 2 / E S D N$ promoter is shown in Figure 4A. This region was amplified from a BAC genomic clone (see Methods) and cloned in a luciferase reporter vector generating the pGL3ESDN-WT (ESDNwt) construct. The effects of TFAP2A on promoter activity were tested by performing reporter assays in HeLa and MDA-MB-231 cell lines expressing, respectively, medium and low levels of TFAP2A as assessed by Western Blot (WB) analyses shown in Figure $4 \mathrm{~B}$ and $4 \mathrm{C}$. Both cell lines were transiently co-transfected with either ESDNwt or its 5' deletant pGL3-ESDN-DEL3 (del3) starting at -950 or pGL3-Basic (basic) control reporter vector and an expression plasmid for TFAP2A, pSP(RSV)TFAP2A (TFAP2A) or its control empty vector (EV) (Figure 4B and 4C). Alternatively HeLa cells (Figure $4 \mathrm{~B})$ were transfected with an expression vector for TFAP2A silencing, pSUPER-TFAP2AshRNA2 (shTFAP2A), or with the empty pSUPER control vector (shEV). In addition, cells were transfected with the pRLTK vector for Renilla luciferase expression, to perform transfection efficiency normalization. TFAP2A basal levels, overexpression or silencing were verified by Western Blot (WB) analyses (Figure 4B and $4 \mathrm{C}$ ) where Glyceraldheyde-3-phosphate dehydrogenase (GAPDH) was used as loading control. 3 fold higher activity was observed for the ESDNwt reporter vector in MDA-MB231 cells compared with HeLa cells (compare Figure 4B with 4C). The inhibitory function of TFAP2A on $D C B L D 2 / E S D N$ gene transcription was further supported when HeLa and MDA-MB-231 cells were cotransfected with ESDNwt and TFAP2A (250 ng, otherwise specified) with respectively 2 and 3.5 fold reduction in luciferase activity (Figure $4 \mathrm{~B}$ and $4 \mathrm{C}$ ). This reduction was inversely proportional to the TFAP2A levels in cells ( 12.5 or 125 or $250 \mathrm{ng}$ ), as shown in Figure 4C for MDAMB-231 cells. Instead, TFAP2A silencing in HeLa cells caused a 1.6 fold increase in reporter activity (Figure 4B). All together these results strongly suggest a direct repressive activity of TFAP2A on DCBLD2/ESDN promoter and are in agreement with our previous microarray results [39].

\section{Specific role of the TFAP2A binding sites present in DCBLD2/ESDN promoter}

A detailed functional analysis was performed for the main TFAP2A binding site present in DCBLD2/ESDN promoter by carrying out site-directed mutagenesis to 


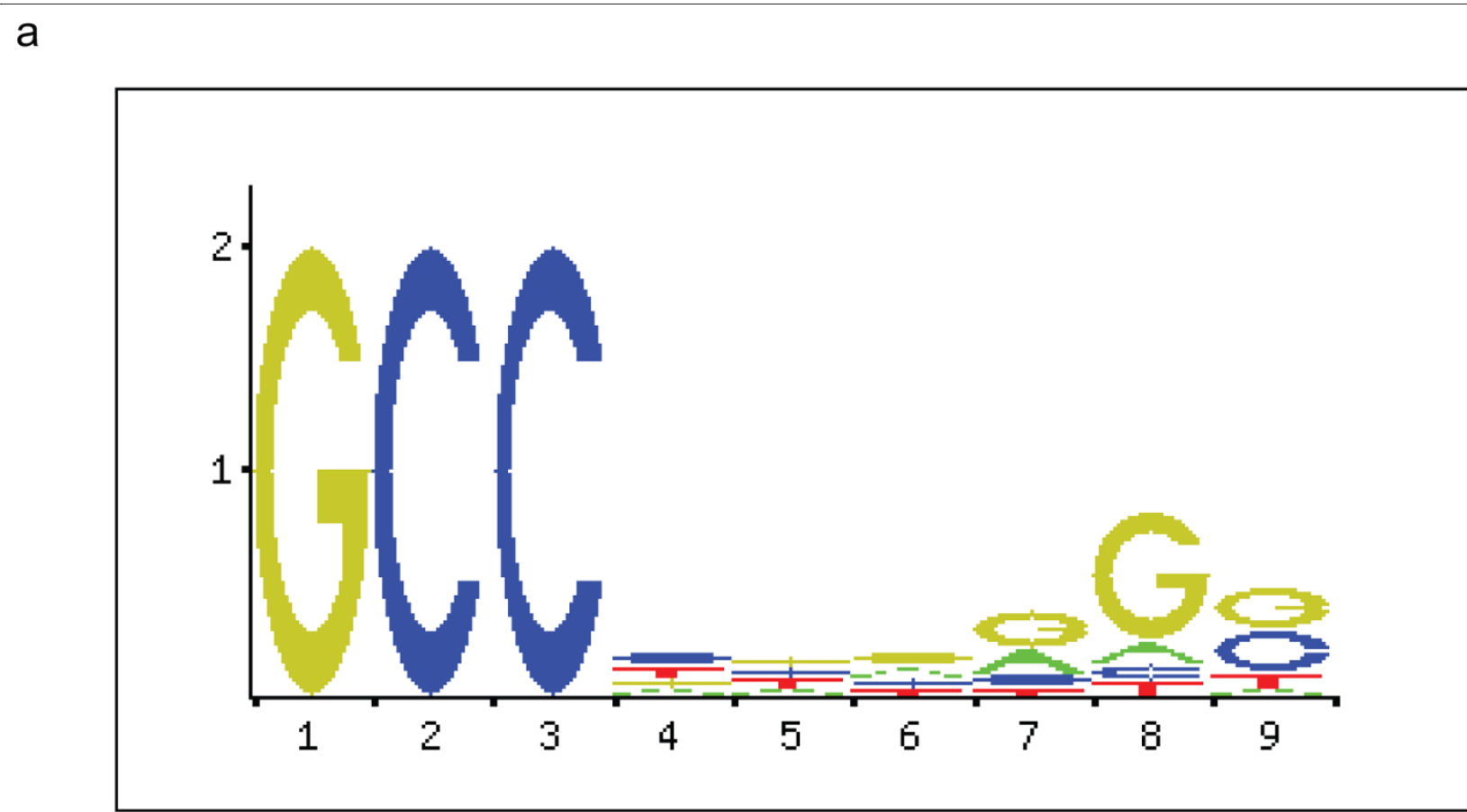

b

\begin{tabular}{|c|c|c|c|c|c|c|c|c|c|}
\hline A & 0 & 0 & 0 & 22 & 19 & 55 & 53 & 19 & 9 \\
\hline $\mathrm{C}$ & 0 & 185 & 185 & 71 & 57 & 44 & 30 & 16 & 78 \\
\hline 0 & [185 & 0 & 0 & 46 & 61 & 67 & 91 & 137 & 79 \\
\hline & 0 & 0 & 0 & 46 & 48 & 19 & 11 & 13 & 19 \\
\hline
\end{tabular}

Figure 1 Sequence logo and canonical Positional Weight Matrix (PWM) of TFAP2A. Logo (A) and frequencies (B) defining the TFAP2A PWM MA0003 are shown as provided by Jaspar database http://jaspar.genereg.net/.

obtain $7 \mathrm{bp}$ deletions in the central portion of each TFAP2A binding site in single or multiple combinations to generate the constructs reported in Figure 5. Mutations in the TFAP2A binding sites 1 or 2 or 3 (ESDNMUT1 or ESDNMUT2 or ESDNMUT3) pro- duced statistically significant increased promoter activity just like mutations for multiple TFAP2A binding sites 1,2 or 1,3 , or 2,3 or $1,2,3$ (ESDNMUT1; ESDNMUT1,2; ESDNMUT1,3; ESDNMUT2,3; ESDNMUT1,2,3) as indicated by the student's $t$ tests: ${ }^{*} \mathrm{p}_{\mathrm{v}}<0.05 ;{ }^{* *} \mathrm{p}_{\mathrm{v}}<0.01$ sug- 

Table 3: TFAP2A binding site sequences present in the regulatory regions of some TFAP2A- modulated genes.

\begin{tabular}{|c|c|c|c|c|c|}
\hline Gene Symbol & ENSEMBL ID & Microarray FC & $\begin{array}{l}\text { TFAP2A binding } \\
\text { sequence }\end{array}$ & $\begin{array}{l}\text { TFAP2A binding } \\
\text { score }\end{array}$ & Position \\
\hline \multirow[t]{2}{*}{$E S D N / D C B L D 2$} & ENSG00000057019 & 5.7 & GCCGCGGGG & 12.74 & -269 \\
\hline & & & GCCCGCAGC & 11.54 & -10 \\
\hline \multirow[t]{7}{*}{ PPARG } & ENSG00000132170 & 2.6 & GCCTGAGGC & 11.48 & -851 \\
\hline & & & GCCGGGGGC & 12.82 & -280 \\
\hline & & & GCCGCGGGG & 12.74 & -176 \\
\hline & & & GCCCCGCGG & 11.77 & -175 \\
\hline & & & GCCGTGGGC & 11.94 & -134 \\
\hline & & & GCCCGGCGC & 11.85 & +10 \\
\hline & & & GCCCGCGGC & 12.85 & +42 \\
\hline EREG & ENSG00000124882 & 2.5 & CCCTCGGGC & 12.75 & -101 \\
\hline \multirow[t]{4}{*}{$C X C L 1$} & ENSG00000163739 & 2.4 & GCCCGGGGG & 13.46 & -64 \\
\hline & & & GCCCCCGGG & 12.76 & -63 \\
\hline & & & GCCCGGAGC & 12.14 & -56 \\
\hline & & & GCCGCAGGC & 11.91 & +13 \\
\hline \multirow[t]{4}{*}{ CD59 } & ENSG00000085063 & 1.7 & GCCCTGGGG & 12.58 & -336 \\
\hline & & & GCCCCAGGG & 12.55 & -335 \\
\hline & & & GCCGGGAGC & 11.51 & -37 \\
\hline & & & GCCGGGGGG & 12.83 & +3 \\
\hline \multirow[t]{2}{*}{ ADAMTS1 } & ENSG00000154734 & 1.7 & GCCCGCAGC & 11.54 & -142 \\
\hline & & & GCCGGGGGC & 12.82 & -107 \\
\hline \multirow[t]{2}{*}{ SLIT2 } & ENSG00000145147 & 1.7 & GCCGGGGGC & 12.81 & -679 \\
\hline & & & GCCCCGAGG & 12.06 & -248 \\
\hline
\end{tabular}


Table 3: TFAP2A binding site sequences present in the regulatory regions of some TFAP2A- modulated genes.

\begin{tabular}{|c|c|c|c|c|c|}
\hline CASP9 & ENSG00000132906 & -1.5 & GCCCTGGGG & 12.58 & -734 \\
\hline & & & GCCCCCAGG & 11.45 & -463 \\
\hline & & & GCCCCCAGG & 11.45 & -370 \\
\hline & & & GCCCGCAGG & 11.55 & -182 \\
\hline & & & GCCCTGGGG & 12.58 & +4 \\
\hline & & & GCCCCCAGG & 11.45 & +69 \\
\hline & & & GCCCCGCGC & 11.75 & +2 \\
\hline \multirow[t]{4}{*}{ TGFBI } & ENSG00000120708 & -1.6 & GCCCTGGGG & 12.58 & -899 \\
\hline & & & GCCCCCAGC & 11.44 & -414 \\
\hline & & & GCCCTGGGC & 12.57 & -212 \\
\hline & & & GCCCTGGGC & 12.57 & +43 \\
\hline GLO1 & ENSG00000124767 & -2.0 & GCCGCGGGC & 12.72 & -24 \\
\hline \multirow[t]{9}{*}{ FASTK } & ENSG00000164896 & -2.2 & GCCCGGAGG & 12.15 & -856 \\
\hline & & & GCCCCGAGC & 12.04 & -500 \\
\hline & & & GCCCGGGGC & 13.45 & -413 \\
\hline & & & GCCCCGGGG & 13.36 & -393 \\
\hline & & & GCCCCCGGG & 12.76 & -391 \\
\hline & & & GCCCTCGGC & 11.97 & -66 \\
\hline & & & GCCCGGCGC & 11.85 & -59 \\
\hline & & & GCCCGCGGG & 12.86 & -42 \\
\hline & & & GCCGGGAGC & 11.51 & -2 \\
\hline \multirow[t]{3}{*}{ KRT16 } & ENSG00000186832 & -2.5 & GCCCTCGGG & 11.98 & -860 \\
\hline & & & GCCCCCGGG & 12.76 & -650 \\
\hline & & & GCCTGAGGC & 11.48 & -502 \\
\hline
\end{tabular}


Table 3: TFAP2A binding site sequences present in the regulatory regions of some TFAP2A- modulated genes.

\begin{tabular}{|c|c|c|c|c|c|}
\hline & & & GCCCCGAGG & 12.06 & -279 \\
\hline & & & GCCCTCGGG & 11.98 & -277 \\
\hline \multirow[t]{4}{*}{ KRT17 } & ENSG00000186831 & -2.7 & GCCCCGGGG & 13.36 & -525 \\
\hline & & & GCCCCGGGG & 13.36 & -524 \\
\hline & & & GCCCCCAGC & 11.44 & -203 \\
\hline & & & GCCTGGGGG & 12.30 & +56 \\
\hline \multirow[t]{2}{*}{$P L C X D 2$} & ENSG00000144824 & -1.5 & CCCCCTTGGC & $9.47^{*}$ & -878 \\
\hline & & & GGCCAGGGC & $9.04 *$ & -64 \\
\hline IFI44 & ENSG00000137965 & -1.9 & - & - & - \\
\hline \multicolumn{6}{|c|}{$\begin{array}{l}\text { For each ChIP-validated TFAP2A target gene or negative control (see figure } 3 \text { and 6) Gene Symbol, ENSEMBL IDs, TFAP2A binding site } \\
\text { sequence, score and position (referring to the TSS as +1) are shown. ADAMTS1: ADAM metallopeptidase with thrombospondin type } 1 \text { motif, } \\
\text { 1; CASP9: caspase 9; CD59: CD59 molecule, complement regulatory protein; CXCL1: chemokine (C-X-C motif) ligand } 1 \text { (melanoma growth } \\
\text { stimulating activity alpha); DCLBD2/ESDN: Endothelial and smooth muscle cell derived neuropiline like molecule; EREG: Epiregulin; FASTK: } \\
\text { fast kinase; GLO1: glyoxalase I; KRT16: keratin 16; KRT17: keratin 17; IFI44: interferon-induced protein 44; PLCXD2: pleckstrin homology-like } \\
\text { domain family B member 2; PPARG: peroxisome proliferator activated receptor gamma; SLIT2: slit homolog } 2 \text { (Drosophila); TGFBI: } \\
\text { Transforming Growth Factor Beta-Induced. * low score binding sites, used as negative controls. }\end{array}$} \\
\hline
\end{tabular}

gesting that each binding site plays a role in repressing the promoter activity.

\section{Identification of Transcription Factor Binding Sites (TFBSs) present in the promoter regions of TFAP2A-regulated genes by over-represented DNA oligonucleotides or oPOSSUM or MEME analysis}

The properties of the core promoter region sequences of the 264 best $20 \%$ TFAP2A-regulated genes were studied by using three different approaches based on different biological assumptions and statistical filters such as: 1) short over-represented oligonucleotides; 2) oPOSSUM; 3) MEME.

\section{Over-represented oligonucleotides}

We performed a genome-wide characterization of the previously described core promoters of human-proteincoding genes, working on the statistical properties of short (5 to $9 \mathrm{nt}$ ) DNA oligonucleotides (oligos) present in these sequences. In particular, we identified sets of genes sharing over-represented oligos in their promoter regions according to a binomial model (see Methods for details). We then characterized the evolutionary properties of these oligos using a "conserved over-representation" approach, an alignment-free methodology applied to human-mouse comparison [41]. The resulting different sets of genes were then compared with the up- and downTFAP2A-regulated gene datasets, described above and the enrichment for oligos in TFAP2A-regulated genes was assessed in the different sets of genes using an exact Fisher test $\left(\mathrm{p}_{\mathrm{v}}<0.05\right)$ as shown in Table 4. Results were ranked according to the corresponding $\mathrm{p}_{\mathrm{v}}$ and the top 10 over-represented oligos are shown in Table 4. For some of these oligos the over-representation is conserved (indicated in Table 4 with an asterisk, ${ }^{*}$ ) suggesting an evolutionarily conserved role for them. When possible, a known TFBS consensus was then associated to each oligo, using the list of TRANSFAC TFBS consensus sequences reported in [42]. Interestingly, as shown in Table 4, some of the most over-represented oligos found for the TFAP2A-down-regulated genes correspond to the SP1 consensus sequence (Fisher test: 7.76E-07; 38 target genes). For the up-regulated genes we found many overrepresented oligos but we were not able to link them to any known TF.

\section{2. oPOSSUM}

oPOSSUM [43] is able to evaluate the over-representation of known TFBS on human/mouse conserved regions. We used this tool to analyze the sets of TFAP2Aregulated genes setting the parameters indicated in Methods. Results are reported in Table 5 for the up- and down-regulated genes separately. A strong enrichment was observed for SP1 (Fisher score: 2.19 10E-05; Z-score: 17.47; 95 target genes) and NHLH1 (Fisher score: 7.09 E- 


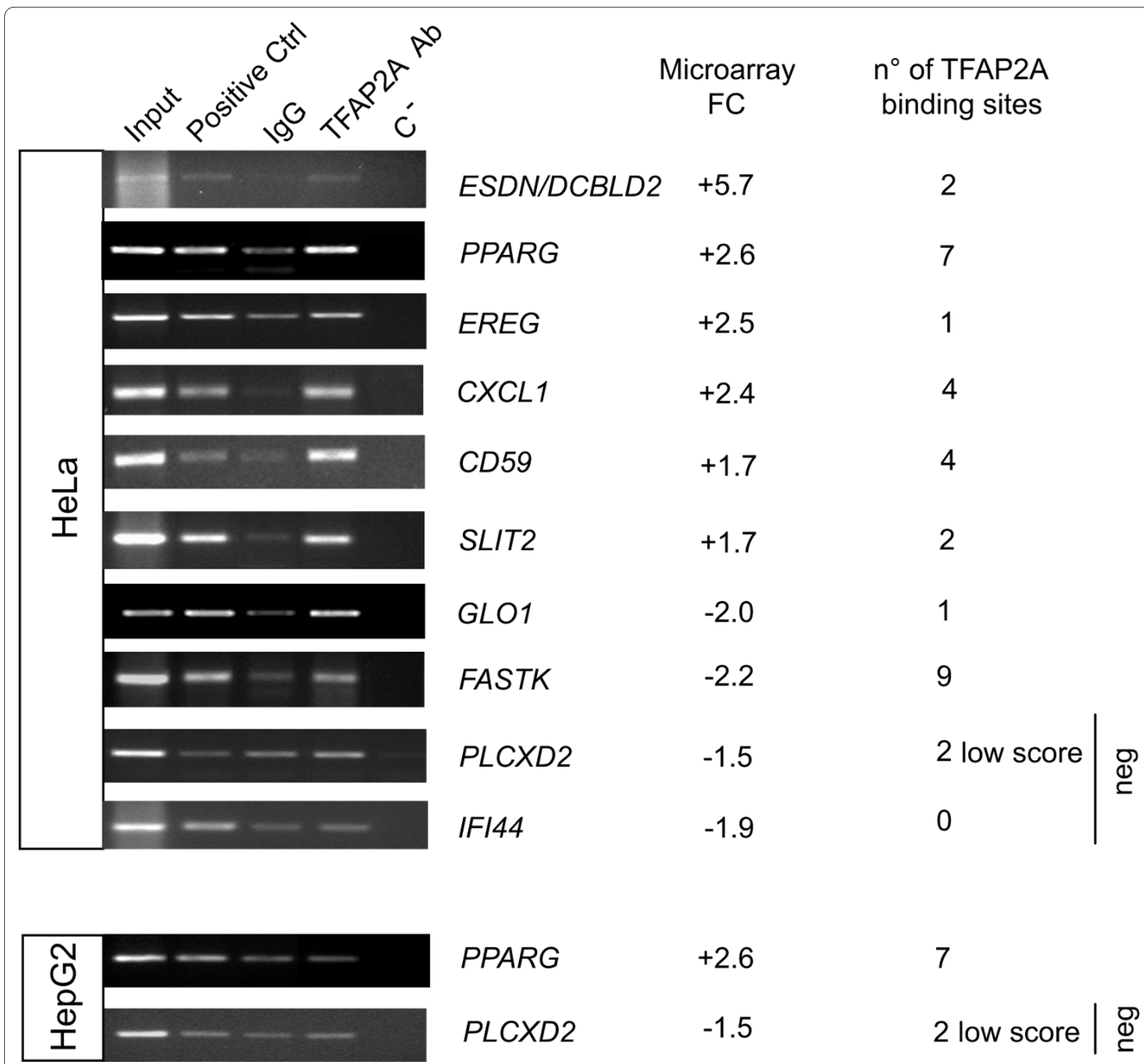

Figure 3 In vivo Chomatin ImmunoPrecipitation (ChIP) analysis for putative TFAP2A binding sites on the core promoters of potential TFAP2A target genes. Pre-cleared chromatin from HeLa or HepG2 cells was immunoprecipitated with either non-specific lgG (lgG, negative control) or anti-RNA polymerase II or anti-acetylhistone H3 (positive controls: Positive Ctrl) or anti-TFAP2A (TFAP2A) antibodies. Immunoprecipitated DNA or non-immunoprecipitated chromatin samples (input) were amplified by PCR using primer pairs designed with the NCBI Primer Designing Tool (see Methods) across the TFAP2A putative binding sites. CD59: CD59 molecule, complement regulatory protein; $C X C L 1$ : chemokine (C-X-C motif) ligand 1 (melanoma growth stimulating activity alpha); DCLBD2/ESDN: endothelial and smooth muscle cell derived neuropilin like molecule; $E R E G$ : epiregulin; FASTK: fast kinase; GLO1: glyoxalase l; IFI44: interferon-induced protein 44; PLCXD2: pleckstrin homology-like domain family B member 2; PPARG: peroxisome proliferator activated receptor gamma; SLIT2: slit homolog 2 (Drosophila). C-, PCR negative control; FC, fold changes obtained from the microarray analysis [39]. Number $\left(n^{\circ}\right)$ of TFAP2A binding sites identified computationally. Three independent experiments were performed and a representative one is shown here.

05; Z-score: 14.76; 44 target genes) on down-regulated genes. An enrichment for Pax5 (Fisher score: 3.31 E-03; Z-score: 9.98; 12 target genes) and Cebpa (Fisher score: 6.67 E-03; Z-score: 8.20 ; 41 target genes) was observed for the up-regulated genes even if the statistical relevance was weaker then what observed for the down-regulated genes.

\section{MEME}

MEME is a software for the $a b$-initio identification of relevant motifs in a given set of sequences in which a motif is a sequence pattern that occurs repeatedly in a group of related DNA sequences [44]. The parameters used in our analysis are indicated in Methods and the results obtained are reported in Table 6: MEME regular expres- 
a

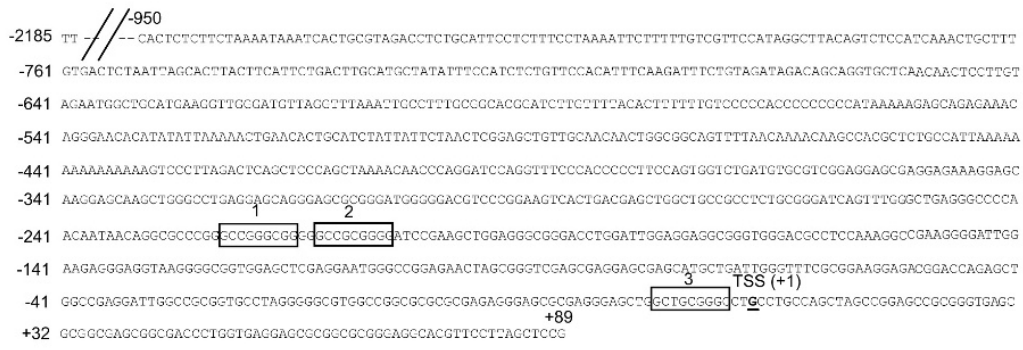

b
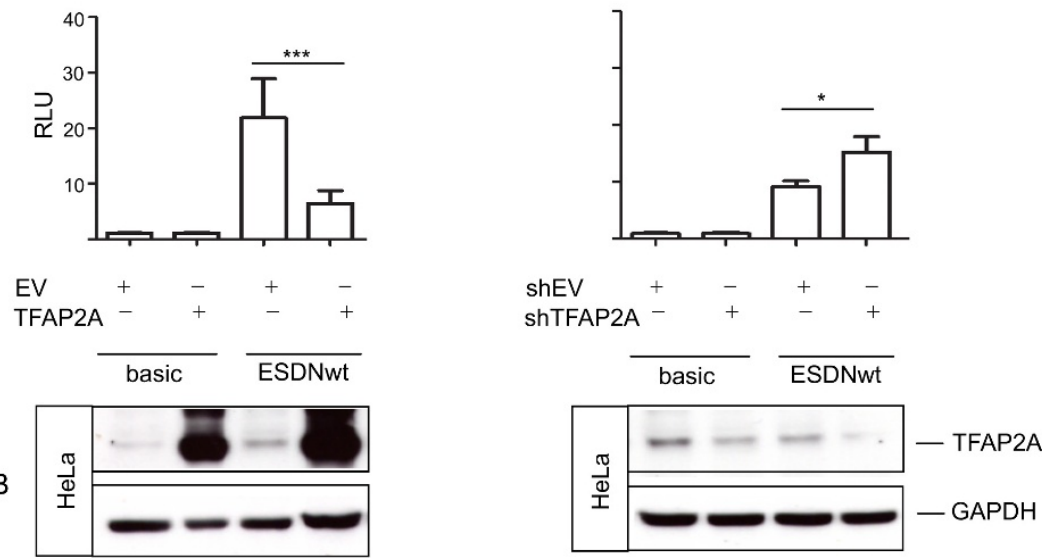

C
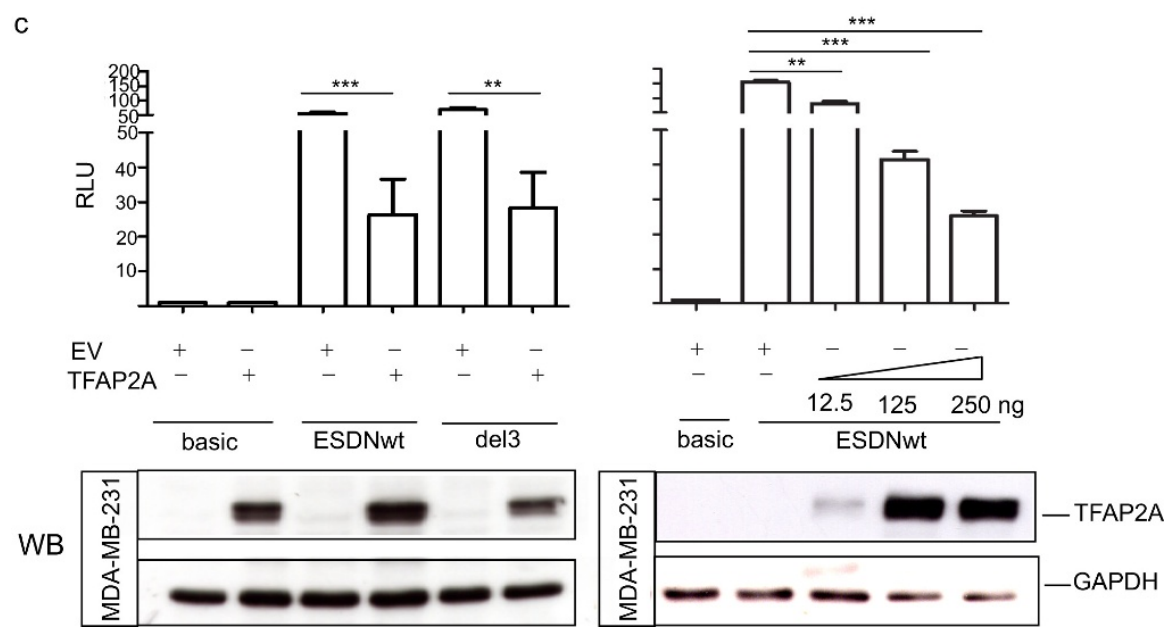

Figure 4 Regulation of the DCBLD2/ESDN promoter by TFAP2A. (A) The genomic organization of the human DCBLD2/ESDN promoter (-2185/+89) is shown and the three highest score TFAP2A binding sites identified are framed and named 1 or 2 or 3 . The Transcription Start Site (TSS) is considered +1. (B)(C) HeLa (B) and MDA-MB-231 (C) cells were transiently co-transfected with either pGL3-Basic (basic) or pGL3-ESDN-WT (ESDNWT) or pGL3ESDN-del3 (del3) vectors together with pSP(RSV)TFAP2A (TFAP2A) or TFAP2AshRNA2 (shTFAP2A) or their respective control empty vectors (EV or shEV) to obtain TFAP2A over-expression or down-modulation. pRLTK (Renilla luciferase) vector was transfected along to evaluate transfection efficiency and perform normalizations. Forty-eight hours later Firefly Luciferase activity was measured and normalized against Renilla Luciferase. Fold Changes were calculated referring to the pGL3-basic control vector and expressed as Relative Luciferase Units (RLUs). 250 ng of TFAP2A or shTFAP2A or EV or shEV were transfected unless specified differently. Three independent experiments were performed in triplicate and a representative one is shown here. The error bars indicate the Standard Errors (SE) of the triplicates. A student's $t$ test was performed to evaluate if the experiments were statistically significant. ${ }^{*} p_{v}<0.05 ;{ }^{* *} p_{v}<0.01 ;{ }^{* * *} p_{v}<0.001$. TFAP2A levels were measured by Western Blot (WB) analysis. Glyceraldheyde-3-phosphate-dehydrogenase (GAPDH) expression was used for protein loading controls. 


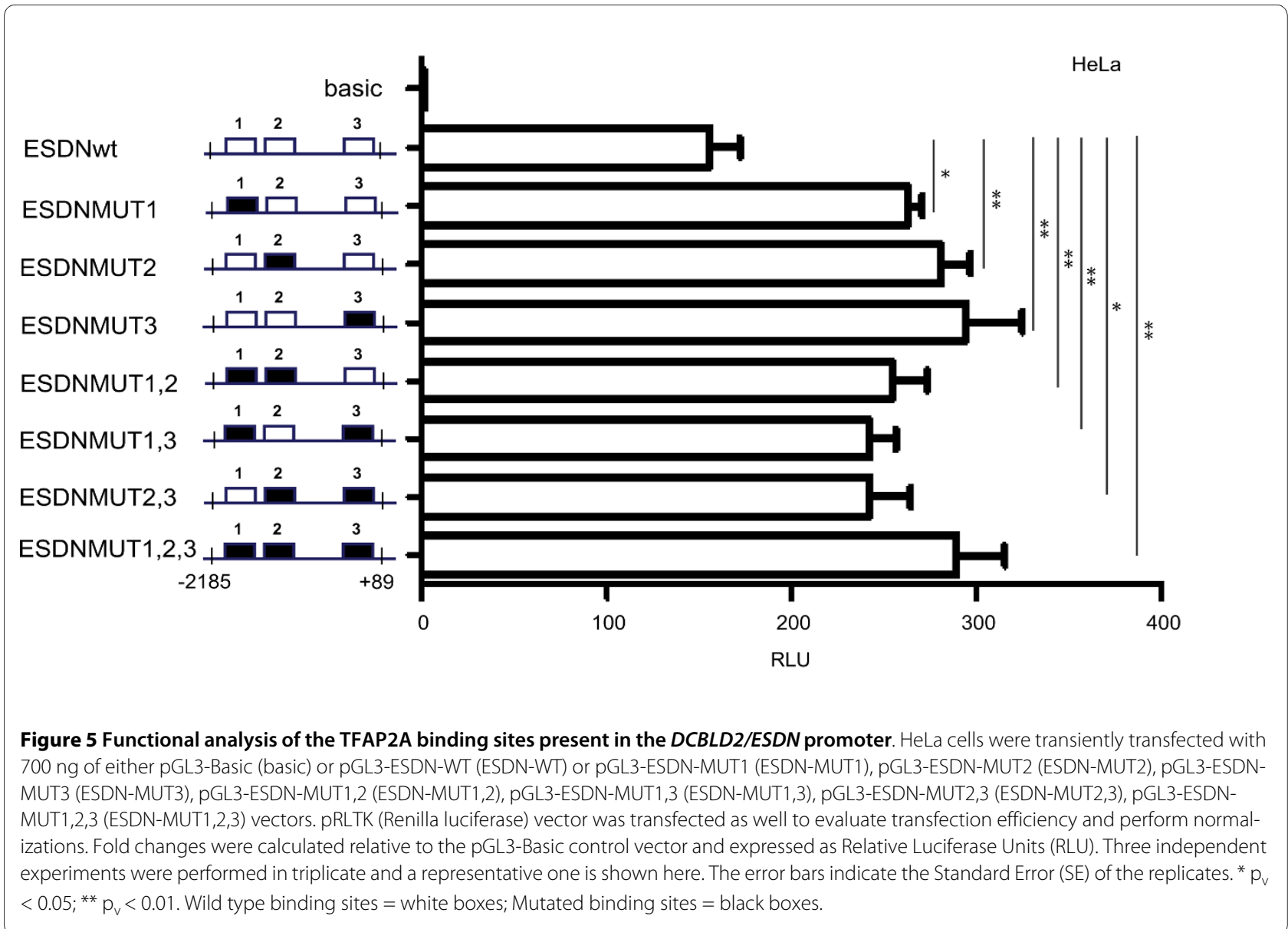

sion motifs and the relative E-values for the most interesting motifs are indicated. MEME results are not directly associated to known TFBSs and to investigate whether the resulting motifs could be recognized as known TFBSs the same approach used previously for the oligo analysis was used here [42]. For this identification, perfect match between MEME regular expression and the IUPAC equivalent was required, as shown in Table 6, and association between motifs and known TFs was found in some cases. Enrichment for SP1 was also found with this method, in particular for down-regulated genes (E-value: 3.1E-085; 24 target genes).

Positioning of the SP1 binding sites in the promoter regions of TFAP2A-down-regulated genes and functional validation

After having observed an enrichment for SP1 binding sites in the 157 TFAP2A-down-regulated genes with the three methods mentioned above, we searched for SP1 sites in the promoter regions of these genes using the same approach employed to recognize TFAP2A binding sites: Jaspar, SP1 Positional Weight Matrix MA0079, cut off on the best $20 \%$ score. 57 genes containing at least one SP1 binding sites were identified and are listed in Table 7.
In the same table it is also indicated if these SP1 motifs were identified with the over-represented oligo or oPOSSUM or MEME approach or not. SP1 binding sites were found in: 2 common genes identified with the oligo analysis and MEME; 12 genes common to oligo analysis and oPOSSUM; 5 genes common to MEME and oPOSSUM; the only common gene to the triple intersection was $O L F M L 2 A$. It is important to underline that SP1 sites did not overlap with TFAP2A binding motifs (data not shown).

Potential SP1 binding was tested for 4 candidate target genes containing one or two best 20\% SP1 and TFAP2A binding sites by Chromatin Immuno Precipitation (ChIP) assay, as indicated by Jaspar PWMs. See Figure 6. The 4 candidate genes were CASP9 (caspase 9); KRT16 (keratin 16); KRT17 (keratin 17) and TGFBI (Transforming Growth Factor B-Induced). ChIP analysis was performed on HeLa cells, using specific anti-SP1 and TFAP2A antibody. As shown in Figure 6, enrichment for SP1 together with TFAP2A was found on the promoter of each gene compared with negative controls, suggesting a functional role for both cis-elements. Negative controls for ChIP analysis were performed using genes where no high score binding sites for either SP1 or TFAP2A were identified 
Table 4: Identification of transcription factor binding sites (TFBSs) present in TFAP2A- modulated genes by overrepresented DNA oligonucleotides.

\begin{tabular}{|c|c|c|c|c|}
\hline $\begin{array}{l}\text { TFAP2A-regulated } \\
\text { genes }\end{array}$ & $\begin{array}{l}\text { Over-represented } \\
\text { oligo }\end{array}$ & TF & $\begin{array}{l}\text { Target } \\
\text { genes }\end{array}$ & p (Fisher test) \\
\hline \multirow[t]{10}{*}{ DOWN n = 157} & $\mathrm{CGGGC}^{*}$ & AP-2alpha, C-Rel, MYB, AMEF-2 & 22 & $1.20 \mathrm{E}-07$ \\
\hline & GAGCCGGC & & 27 & $1.48 \mathrm{E}-07$ \\
\hline & $\mathrm{CCCGC}^{*}$ & OLF-1, AP-2alpha, Sp-1,TCF-1(P),EGR & 38 & $7.76 \mathrm{E}-07$ \\
\hline & CCCGGC* $^{*}$ & AP-2alpha, MTF-1 & 47 & $1.20 \mathrm{E}-06$ \\
\hline & CCCCGAGG* & AP-2alpha & 51 & 4.57E-06 \\
\hline & $\mathrm{CGGCA}^{*}$ & AP-2alpha & 57 & $7.08 \mathrm{E}-06$ \\
\hline & CCCATCCTA & & 64 & 1.17E-05 \\
\hline & CGGCAGCC & & 65 & $1.51 \mathrm{E}-05$ \\
\hline & GCCCGC $^{*}$ & AP-2alpha & 66 & $2.45 \mathrm{E}-05$ \\
\hline & CGGGTGCTC & & 70 & $2.75 \mathrm{E}-05$ \\
\hline \multirow[t]{10}{*}{ UP $n=107$} & AAGCGCG* & & 6 & $8.32 \mathrm{E}-06$ \\
\hline & GGGGACTAA & & 11 & $1.62 \mathrm{E}-05$ \\
\hline & AGACGTCT & & 16 & $2.04 \mathrm{E}-05$ \\
\hline & AAACAACAG* & & 21 & 4.27E-05 \\
\hline & ACCCACGCG* & & 26 & $5.13 \mathrm{E}-05$ \\
\hline & CGGGGTAGA & & 29 & $5.89 \mathrm{E}-05$ \\
\hline & CCTGTTTCG* & & 33 & $6.92 \mathrm{E}-05$ \\
\hline & CCGGAG & & 40 & $7.08 \mathrm{E}-05$ \\
\hline & ACGGGTTCT & & 42 & 7.59E-05 \\
\hline & CCGGAGGC & AP-2alpha & 43 & $8.13 \mathrm{E}-05$ \\
\hline
\end{tabular}

For each TF its consensus binding site sequence, abbreviated name, number of target genes and statistical enrichment values (Fisher-score) are reported. ${ }^{*}$ conserved over-represented oligo 
Table 5: Identification of transcription factor binding sites (TFBSs) present in TFAP2A- modulated genes by opossum.

\begin{tabular}{|c|c|c|c|c|c|}
\hline TFAP2A-regulated genes & OPOSSUM matrix (Jaspar CORE) & TF & Target genes & p (Fisher test) & Z-score \\
\hline \multirow[t]{5}{*}{ DOWN $n=157$} & MA0079 & SP1 & 95 & 2.19E-05 & 17.47 \\
\hline & MA0048 & $\mathrm{NHLH} 1$ & 44 & 7.09E-05 & 14.76 \\
\hline & MA0006 & Arnt-Ahr & 99 & $3.21 \mathrm{E}-02$ & 14.25 \\
\hline & MA0056 & MZF1_1-4 & 119 & 4.44E-02 & 11.27 \\
\hline & MA0018 & CREB1 & 45 & $9.48 \mathrm{E}-03$ & 10.63 \\
\hline \multirow[t]{5}{*}{ UP $n=107$} & MA0014 & Pax5 & 12 & 3.31E-03 & 9.98 \\
\hline & MA0102 & Cebpa & 41 & 6.67E-03 & 8.20 \\
\hline & MA0042 & FOXI1 & 35 & $2.12 \mathrm{E}-01$ & 8.00 \\
\hline & MA0135 & Lhx3 & 32 & 2.11E-01 & 7.74 \\
\hline & MA0047 & Foxa2 & 35 & $1.93 \mathrm{E}-01$ & 7.73 \\
\hline
\end{tabular}

For each TF its Positional Weight Matrix (PWM) numbers, abbreviated name, number of target genes and statistical enrichment values (Zscore, Fisher-score) are reported.

such as ADAMTS1 (ADAM metallopeptidase with thrombospondin type 1 motif, 1 ) and PLCXD2 (pleckstrin homology-like domain family B member 2). Enrichment for TFAP2A but not for SP1 was found for ADAMTS1 while no enrichment for both TFs was observed for PLCXD2.

\section{Discussion}

The results presented in this work show how powerful an in silico approach can be for the identification of functional Transcription Factor Binding Sites (TFBSs), in particular when computational investigations are associated with microarray analysis. In fact, while microarray analysis is, by definition, not able to discriminate between direct or indirect Transcription Factor (TF) gene expression modulation [45], the positioning of TFBSs on differentially expressed genes allows the identification of genes directly regulated by the TF of interest. By analyzing gene expression profiles on HeLa cells either silenced for TFAP2A by RNA interference or not [39] we were previously able to identify a subset of new TFAP2A regulated genes on which it was possible to position high score TFAP2A binding sites and find an enrichment of sites compared with genome-wide $[5,6]$. The strength of our computational approach was consolidated by experimental validations revealing TFAP2A binding to the high score TFAP2A sites identified but not to portions of DNA without TFAP2A binding sequences or containing only low score sites.

A network analysis performed with Ingenuity Pathway Analysis Systems for the TFAP2A-modulated genes containing at least two high score TFAP2A binding sites revealed "Cellular Movement" and "Cellular Development" as the main networks confirming results previously obtained in our and other laboratories. In fact, many reports demonstrated that TFAP2A plays a major role in development [12] and we recently showed a function for TFAP2A in cell migration and/or invasion for tumor cells [39] and neurons [46]. Genes involved in both biological processes were previously identified however several new ones have been discovered here. Among the already known genes, PPARG, MAPK1, and VEGF [47] are present in the networks confirming the validity of our analysis.

The "Cellular Movement" network includes genes with specific biological functions and some examples are listed here. SLIT2 (slit homolog 2 -Drosophila) is involved in induction of negative chemotaxis in neuronal cells, glial cell migration, motor axon guidance and nervous system development [48]. PDGFs (platelet-derived growth factors) are known to regulate cell proliferation as well as migration for mesenchymal or endothelial cells [49]. 
Table 6: Identification of transcription factor binding sites (TFBSs) present in TFAP2A- modulated genes by MEME analysis.

\begin{tabular}{|c|c|c|c|c|}
\hline $\begin{array}{l}\text { TFAP2A-regulated } \\
\text { genes }\end{array}$ & MEME regular expression & TF & Target genes & MEME E-value \\
\hline \multirow[t]{6}{*}{ DOWN $n=157$} & [GA]CCTGTA[AG]TCCCAGC[TA][CA][CT]T[TC] & PITX2, CRX & 26 & $9.1 \mathrm{E}-162$ \\
\hline & AT[CT]CTCC[TC][GA]CCTC[AG]G & & 34 & $2.6 \mathrm{E}-058$ \\
\hline & 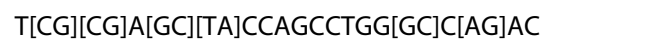 & & 29 & 4.3E-104 \\
\hline & AGG[TC]TGCAGTGAGC[CT]G[AT]GAT & Sp-1, AP-2apha, MAZ, TFII-I & 24 & 3.1E-085 \\
\hline & $\mathrm{GG}[\mathrm{GA}] \mathrm{GG}[\mathrm{CA}] \mathrm{GGGG}[\mathrm{CGA}][\mathrm{GC}] \mathrm{GG}[\mathrm{GA}][\mathrm{GAC}] \mathrm{G}[\mathrm{GAC}] \mathrm{GG}$ & & 38 & 1.7E-056 \\
\hline & GTGAGCCAC[CT][GA]CGCCCGGC[CT] & & 21 & $2.0 \mathrm{E}-049$ \\
\hline \multirow[t]{8}{*}{ UP $n=107$} & CTCCC[AG]A[AG][GT][TA]GCTGGGA[TC]TA & MYOD, PITX2, CRX & 20 & $2.1 \mathrm{E}-126$ \\
\hline & GT[CT]TC[AG]C[TC][AC]TGT[TC][GA][CG]CCAGG & YY1, AP-2alpha & 22 & $1.5 \mathrm{E}-082$ \\
\hline & $\mathrm{G}[\mathrm{GC}] \mathrm{GGCGG}[\mathrm{GC}] \mathrm{G}[\mathrm{GC}][\mathrm{CG}] \mathrm{GG}[\mathrm{GC}] \mathrm{GG}[\mathrm{CG}] \mathrm{GG}[\mathrm{GC}]$ & Sp-1, AP-2alpha & 35 & 9.7E-062 \\
\hline & [GT]TGTGTGTG[TC]G[TC][GA][TC]GTGTG[TG] & MYC & 9 & $3.2 \mathrm{E}-016$ \\
\hline & G[GC][TC]TCAAG[CT]GAT[TC]CTCC[TC]GC & NKX2-5 & 16 & $1.5 \mathrm{E}-049$ \\
\hline & CAGG[CT]G[TC]G[AC]GCCACC[GA]C[GA]CC & AREB6, AML1 & 19 & 7.7E-067 \\
\hline & ATCT[CT][GA]GCTCACTGCA[AG]CCT & & 16 & $9.8 \mathrm{E}-048$ \\
\hline & TGGTCTCGA[TA]CTCCTGACCT & T3R, ER & 12 & $8.0 \mathrm{E}-032$ \\
\hline
\end{tabular}

Interestingly, in vascular cells $P D G F B B$ is known to upregulate $D C B L D 2 / E S D N$ (discoidin, CUB and LCCL domain containing 2/Endothelial and Smooth muscle cell Derived Neuropin-like molecule), the most TFAP2Amodulated gene in our microarray analysis. $P D G F B B$ is also known to be related to another TFAP2A-modulated gene, ACTA2 (actin, alpha 2, smooth muscle, aorta), which codes for a protein belonging to the actin family that plays a role in cell motility, structure and integrity and regulates blood pressure via vascular and smooth muscle contraction [50]. RAC1 and RAC2 (ras-related C3 botulinum toxin substrate 1 and 2) are small GTPases belonging to the RAS superfamily and regulate a variety of cellular events, including growth control, cytoskeletal reorganization and protein kinase activation [51]. PDGF and $R A C 1$ are connected with each other since it was demonstrated that all RAC1-related GTPases expressed in mouse primary fibroblasts, Cdc42, Rac1, and RhoG, are required for efficient migration following PDGF stimulation [52].

Some of the genes included in Cellular Development network are: PPARs (peroxisome proliferator-activated receptors) form heterodimers with retinoid $\mathrm{X}$ receptors (RXRs) and regulate the transcription of various genes. Three subtypes of PPARs are known: PPARA, PPARD and $P P A R G$. The last one regulates adipocyte differentiation and is involved in the pathology of numerous diseases including obesity, diabetes, atherosclerosis and cancer [53]. MAPK1 (mitogen-activated protein kinase 1) is a member of the MAP kinase family and it is involved in cellular proliferation, differentiation, transcription regulation and development [54]. CXCL1 (chemokine, C-X-C 
Table 7: Summary of TFAP2A-down-modulated genes containing SP1 binding sites in their promoters

\begin{tabular}{|c|c|c|c|c|c|}
\hline \multicolumn{6}{|c|}{ Down-modulated genes containing SP-1 binding sites } \\
\hline ENSEMBL ID & Gene symbol & Microarray FC & Oligo & oPOSSUM & MEME \\
\hline ENSG00000092871 & RFFL & -1.5 & - & - & - \\
\hline ENSG00000 & SLCO4 & -1.5 & - & - & - \\
\hline ENSG00000 & C16or & -1.5 & - & + & - \\
\hline ENSG00000 & CDK6 & -1.5 & - & + & - \\
\hline ENSG00000 & GCN5L & -1.5 & - & + & - \\
\hline ENSG00000 & ATP8B & -1.5 & - & - & - \\
\hline ENSG00000 & CASP9 & -1.5 & + & - & - \\
\hline ENSG00000 & SPOCK & -1.5 & + & + & - \\
\hline ENSG00000 & FBN1 & -1.5 & - & + & - \\
\hline ENSG00000 & SMAD3 & -1.5 & + & + & - \\
\hline ENSG00000 & PHLDA & -1.5 & - & + & - \\
\hline ENSG00000 & $D A L R D$ & -1.5 & + & + & - \\
\hline ENSG00000 & GPRC5 & -1.6 & - & - & + \\
\hline ENSG00000 & $K I A A 1$ & -1.6 & - & - & - \\
\hline ENSG00000 & COL12 & -1.6 & - & + & - \\
\hline ENSG00000 & TGFBI & -1.6 & - & - & - \\
\hline ENSG00000 & RDH10 & -1.6 & + & + & - \\
\hline ENSG00000 & MESP1 & -1.6 & - & - & - \\
\hline ENSG00000 & OPLAH & -1.6 & + & + & - \\
\hline ENSG00000 & ST4S6 & -1.6 & - & + & + \\
\hline ENSG00000 & $B C O R$ & -1.6 & + & + & - \\
\hline ENSG00000 & RPS27 & -1.6 & - & + & + \\
\hline ENSG00000 & $S L C 25$ & -1.6 & + & - & - \\
\hline
\end{tabular}


Table 7: Summary of TFAP2A-down-modulated genes containing SP1 binding sites in their promoters (Continued)

\begin{tabular}{|c|c|c|c|c|c|}
\hline ENSG00000 & PDGFA & -1.6 & + & + & - \\
\hline ENSG00000 & DNMT3 & -1.7 & - & + & - \\
\hline ENSG00000 & $E P B 41$ & -1.7 & + & + & - \\
\hline ENSG00000 & CDKN1 & -1.7 & + & + & - \\
\hline ENSG00000 & TMEM1 & -1.7 & - & + & - \\
\hline ENSG00000 & RNF38 & -1.7 & - & - & - \\
\hline ENSG00000 & $S L C 27$ & -1.7 & + & - & - \\
\hline ENSG00000 & SLC43 & -1.7 & + & + & - \\
\hline ENSG00000 & DPYSL & -1.8 & - & + & - \\
\hline ENSG00000 & $S L C 7 A$ & -1.8 & - & - & - \\
\hline ENSG00000 & PXDN & -1.8 & - & - & - \\
\hline ENSG00000 & COL5A & -1.8 & + & + & - \\
\hline ENSG00000 & SECTM & -1.8 & + & - & - \\
\hline ENSG00000 & GLS & -1.9 & - & + & - \\
\hline ENSG00000 & ENAH & -1.9 & - & + & - \\
\hline ENSG00000 & FTH1 & -1.9 & - & - & - \\
\hline ENSG00000 & SYNGR & -2.0 & - & + & + \\
\hline ENSG00000 & TXNIP & -2.0 & - & + & - \\
\hline ENSG00000 & LOXL2 & -2.0 & - & - & - \\
\hline ENSG00000 & STX6 & -2.0 & - & + & + \\
\hline ENSG00000 & $R A B 15$ & -2.0 & + & - & - \\
\hline ENSG00000 & COX6B & -2.0 & - & - & - \\
\hline ENSG00000 & OLFML & -2.0 & + & + & + \\
\hline ENSG00000 & PAG1 & -2.1 & - & + & - \\
\hline
\end{tabular}


Table 7: Summary of TFAP2A-down-modulated genes containing SP1 binding sites in their promoters (Continued)

\begin{tabular}{|c|c|c|c|c|c|}
\hline ENSG00000 & SESN1 & -2.1 & - & + & - \\
\hline ENSG00000 & ACTA2 & -2.1 & - & - & - \\
\hline ENSG00000 & ANXA8 & -2.2 & - & - & - \\
\hline ENSG00000 & ZFAND & -2.3 & - & + & - \\
\hline ENSG00000 & KRT16 & -2.5 & - & + & - \\
\hline ENSG00000 & $J M J D 3$ & -2.6 & - & + & - \\
\hline ENSG00000 & PLSCR & -2.7 & + & - & + \\
\hline ENSG00000 & USP18 & -2.7 & - & - & + \\
\hline ENSG00000 & KRT17 & -2.7 & - & - & - \\
\hline ENSG00000127129 & EDN2 & -3.2 & - & + & - \\
\hline
\end{tabular}

motif, ligand 1 - melanoma growth stimulating activity, alpha) belongs to the Chemokine family, a group of small, structurally related molecules that regulate cell trafficking of various types of leukocytes via the interaction with a subset of 7-transmembrane, G protein-coupled receptors [55]. In addition, $C X C L 1$ is known to play a major role in inflammation, angiogenesis, tumorigenesis and wound healing [56]. ADAMTS1 (a disintegrin-like and metalloprotease with thrombospondin type 1 motif, 1 ) gene encodes for a member of the ADAMTS protein family that has anti-angiogenic activity and the expression of this gene may be associated with various inflammatory processes as well as development of cancer and cachexia [57]. The protein encoded by the AREG (amphiregulin) gene is a member of the epidermal growth factor (EGF) family involved in cell growth stimulation of astrocytes, Schwann cells, fibroblasts and epithelial cells by interacting with EGF receptor [58]. IL11 (interleukin 11) encodes for a cytokine which stimulates the T-cell-dependent development of immunoglobulin-producing $\mathrm{B}$ cells and potentiates proliferation of hematopoietic stem cells and megakaryocyte progenitors [59].

Since it is well known that TFAP2A cooperates with other transcription factors (TFs) to regulate transcription, three different methods, over-represented oligonucleotides, oPOSSUM and MEME, were used to identify TF which could possibly work in cooperation with
TFAP2A to regulate the 264 genes containing the best score TFAP2A binding sites. Remarkably a common enrichment for SP1 binding sites was found in genes containing at least one or two high score TFAP2A binding sites and transcriptionally activated by TFAP2A but not in the repressed ones. SP1 is known to cooperate with TFAP2A in transcription [60,61], however here we underline the importance of SP1 specifically in TFAP2A gene activation, but not in transcriptional repression and localize SP1 binding sites to DNA nucleotide sequences distinct from TFAP2A binding sites, although, from our experiments, we cannot exclude the possible physical interaction between TFAP2A and SP1.

Among the ChIP validated genes, the gene encoding for Discoidin, CUB and LCCL domain containing 2/ Endothelial and Smooth muscle Derived Neuropilin like $(D C B L D 2 / E S D N)$ resulted the most modulated in our microarray analysis with a $(F C+5.7)$. This is one of the reasons why we decided to investigate its TFAP2Adependent transcription in detail together with its interesting functions. Its protein structure resembles that of neuropilins, transmembrane proteins which are promiscuous for ligands and co-receptors. DCBLD2/ESDN is ubiquitously expressed but linked to metastasis formation since it has been cloned and found to be significantly up-regulated from highly metastatic lung cancer cells [62]. Various functional studies link DCBLD2/ESDN to 


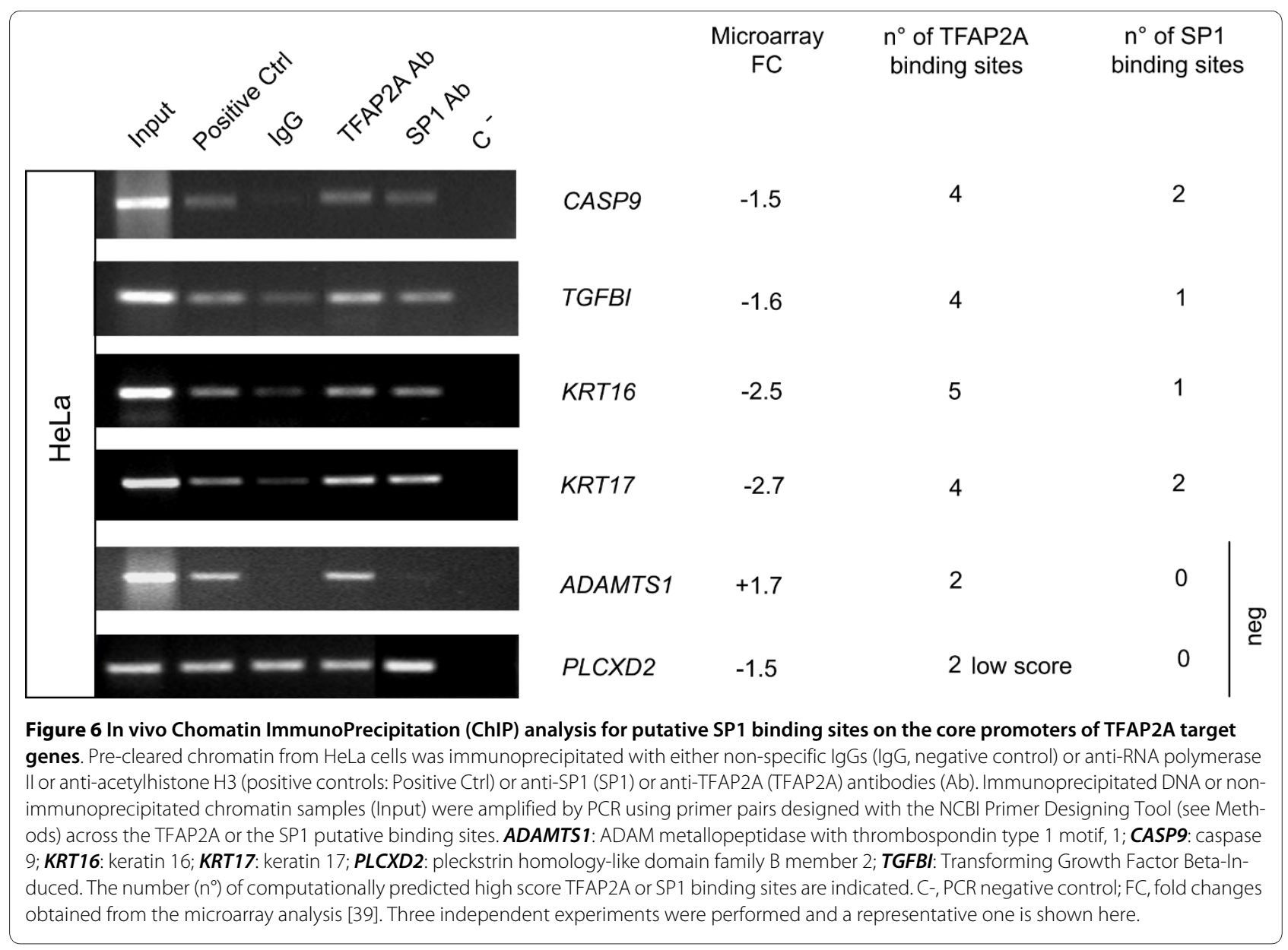

tumor progression but a specific role in tumor promotion or repression has not been defined yet [63,64]. DCBLD2/ ESDN expression was analyzed in our (unpublished data) and other laboratories $[63,65]$ in melanoma and breast cell lines and found to be expressed only in highly metastatic cells but not in their related poorly malignant variants suggesting a positive role for DCBLD2/ESDN in tumor progression. $D C B L D 2 / E S D N$ was also shown to be part of an invasive breast cancer gene signature [66]. However in HeLa cells, used for our microarray analysis, we demonstrated that TFAP2A regulates tumor cell motility and invasion, at least partially, via $D C B L D 2 /$ $E S D N$ in a negative manner [39]. Here TFAP2A downmodulation prompted $D C B L D 2 / E S D N$ up-regulation, suggesting a possible direct repressive effect of $D C B L D 2 /$ $E S D N$ transcription by TFAP2A. In our present investigation, overexpression of TFAP2A in cells expressing low or high levels of TFAP2A, respectively MDA-MD-231 and HeLa cells, led to decreased DCBLD2/ESDN promoter activity although in MDA-MB-231 cells DCBLD2/ESDN promoter activity was higher in comparison with HeLa cells. Accordingly TFAP2A silencing induced higher $D C B L D 2 / E S D N$ promoter activity. Importantly, the nega- tive effect of TFAP2A on $D C B L D 2 / E S D N$ promoter was dose-dependent since when MDA-MB-231 cells were transfected with increasing levels of the TFAP2A-expression vector, a proportional down-regulation of transcription was observed. All together, these findings strongly suggest a direct repressive activity of TFAP2A on $D C B L D 2 / E S D N$ promoter and are in agreement with our microarray results [39]. For these reasons we made the hypothesis that if TFAP2A represses DCBLD2/ESDN transcription, inverse expression profiles should exist for the two genes and therefore we used an on-line expression atlas for RNA expressions in tumors http:// biogps.gnf.org. In some case high $D C B L D 2 / E S D N$ expression coincided with very low levels of TFAP2A in tumor cells, while in other cases $D C B L D 2 / E S D N$ high or low expression co-existed with high TFAP $2 A$ expression. In addition, for many tumors both genes showed comparable TFAP $2 A$ low or medium RNA levels. Since it is known that TFAP2 activity can be modulated by a wide range of interacting proteins [12], it is conceivable that differential expression and functional roles of TFAP2A co-factors may account for distinct effects on $D C B L D 2 /$ $E S D N$ gene transcription. Moreover, the presence of 
other TFAP2 isoforms and the relative ratios with one another may be crucial here. On the other hand, in many cases, both TFAP2A and DCBLD2/ESDN genes might not be expressed. Finally, it is important to keep in mind that RNA levels do not always correspond to actual protein levels or activity. For instance, TFAP2 proteins are known to be modified post-translationally by phosphorylation, sumoylation and redox status, which may affect their activity and cellular localization [12].

Three high and several low score TFAP2A binding sites were identified in the promoter region of the DCBLD2/ $E S D N$ gene by computational analysis however we only investigated the functional role and contribution of the main TFAP2A binding sequences. By doing so we observed that each TFAP2A site was essential for repression of $D C B L D 2 / E S D N$ transcription, in fact the inactivation of one or two or three site/s equally affected promoter activity in luciferase assays. These experimental validations, confirm once again, that our computational analyses represent a powerful tool for the identification of TF regulatory targets by predicting precisely their cis-elements [19]. To better understand the repressive effect of TFAP2A on DCBLD2/ESDN transcription, the interaction of TFAP2A with other co-factors will be studied in the future. A better comprehension of the TFAP2A-driven regulation of the DCBLD2/ESDN gene should provide novel and useful insights on mechanisms of tumor progression and metastasis formation.

\section{Conclusions}

Our study was essential for: 1) identifying functional TFAP2A binding sites in novel TFAP2A-regulated genes; 2) defining "Cellular Movement" and "Cellular Development" as the main networks in which the TFAP2A target genes are involved; 3) associate SP1 to TFAP2A gene transcription activation but not repression; 4) dissecting the TFAP2A-driven regulation of $D C B L D 2 / E S D N$, an important player of tumor progression.

\section{Methods}

Definition of promoter sequences and TFAP2A binding site identification genome-wide

Whole-genome human protein-coding gene sequences and annotations were downloaded from the ENSEMBL database, version 46, [67]. Only the longest transcript was considered for each gene and the promoter region defined as 900 bps upstream and 100 bps downstream of the Transcriptional Start Site (TSS), +900/-100 [68]. Each promoter sequence was analyzed using the canonical TFAP2A Position Weight Matrix (PWM) MA0003 reported in Jaspar database http://jaspar.genereg.net/ which consists of a 9 nucleotide GC-rich sequence. Affinity scores were assigned to each TFAP2A binding site using a standard log-likelihood ratio (LLR) scoring func- tion with intergenic background frequencies. All sites with score exceeding $66 \%$ of the maximum possible score for the PWM were initially selected, then ranked by score. We considered the top ranking sites (the thresholds used were $10 \%, 20 \%$ and $30 \%$ ) to identify genes carrying at least two high score sites in their regulatory region. The software described in [69] was used to rank the sites.

Identification of TFAP2A potential co-factors in the (-900/ +100 ) promoter regions using three different approaches 1) Over-represented and Conserved Oligonucleotides (Table 4)

We first classified human and mouse genes in two categories (CG-rich and CG-poor) by analyzing the CG content of their promoters using the median CG content of the whole dataset as threshold. The two categories of genes were then independently searched for over-represented 5 to $9 \mathrm{bps}$-long oligonucleotides (oligos) where the overrepresentation was assessed using a binomial model [70] and the overall frequency $f(w)$ of each oligo $w$ was computed as:

$$
f(w)=\frac{N(w)}{N}
$$

where $N(w)$ is the number of times that $w$ occurs in the entire collection of sequences and $N=\sum_{w} N(w)$. Instead $n_{g}(w)$ is the number of occurrences of $w$ in the promoter region of each gene $g$. The statistical significance of over-representation was determined using the binomial P-value:

$$
P_{g}(w)=\sum_{k=n_{g}(w)}^{n_{g}}\left(\begin{array}{c}
n_{g} \\
k
\end{array}\right) f(w)^{k}(1-f(w))^{n_{g}-k}
$$

where

$$
n_{g}=\sum_{w} n_{g}(w)
$$

is the total number of oligos of the same length as $w$ that can be found in the promoter region of $g$. Self-overlapping matches of the same oligo were discarded and motifs were counted on both DNA strands. For each oligo $w$ we defined the set $S(w)$ of the genes whose promoter shows overrepresentation of $w\left(P_{g}(w)<0.01\right)$

An oligo $(w)$ was defined "conserved over-represented" if the sets of genes $S_{\text {human }}(w)$ and $S_{\text {mouse }}(w)$ contained a significantly larger number of orthologous genes than expected by chance. Pairs of human-mouse orthologous 
genes were obtained from ENSEMBL. In order to obtain one-to-one orthology relationships, only orthologous genes defined as Unique Blast Reciprocal Hit were considered. The significance of the overlap between $S_{\text {human }}(w)$ and $S_{\text {mouse }}(w)$ was determined with the exact Fisher test, and multiple testing taken into account by computing the False Discovery Rate (FDR) with the method of Benjamini and Yekutiely [71]. For further analysis we retained the oligos with FDR $<0.1$. Additional details on this procedure can be found in $[41,72]$. In order to identify possible TFAP2A co-factors a direct comparison of the over-represented oligo sequences with the known consensus sequences for vertebrate Transciption Factors (TFs) [42] was performed and the association between motifs and TFs was accepted only if the overrepresented oligo fully overlapped (according to the IUPAC alphabet).

\section{2) oPOSSUM (Table 5)}

The oPOSSUM program [43] was used to identify Transcription Factor Binding Sites (TFBS) recognized by potential TFAP2A co-factors considering $60 \%$ sequence conservation between human and mouse as a minimum requirement. With this approach the regulatory region explored coincided with the smallest cut off we could choose $(-2000 / 0)$ even if it included additional upstream bps compared with the over-represented oligo (see above) and MEME analyses (see below). The other parameters were left unchanged. A Fisher's exact test with a $\mathrm{p}_{\mathrm{v}}<0.05$ was performed here to identify the highly enriched TFBS [43].

\section{3) MEME (Table 6)}

The MEME program [44] was used to identify TFAP2A potential co-factors considering $20 \mathrm{bps}$ as the maximum length of any motif (to fit the standard size of a typical TFBS) and searching for motifs in both DNA strands. To assess whether the motifs obtained by MEME may be associated to any known TFBSs, each motif was associated to a putative TF based on [42].

\section{Localization of SP1 TFBS in the $(-900 /+100)$ promoter regions}

Using the three approaches mentioned above it was possible to identify an enrichment for SP1 TFBS in the promoter regions of 157 TFAP2A-down-modulated genes mapped in ENSEMBL containing at least two high-score TFAP2A binding sites (see Table 1). In order to position the SP1 TFBS an additional analysis using the JASPAR PWM for SP1 (MA0079) was performed on the (-900/ $+100)$ promoter regions of this group of down-regulated genes, as described for TFAP2 (see above).

\section{Cell lines, Antibodies and DNA constructs}

The following human cell lines were used; their origins and general properties, as illustrated by American Type
Culture Collection (ATCC, Manassas, VA, USA), are as follows: HeLa: cervix adenocarcinoma (AC), HPV-18 positive; MDA-MB-231: breast AC, pleural effusion; HepG2 (Human Caucasian hepatocyte carcinoma). Each cell line was grown as suggested by ATCC. Primary antibodies used were anti-: TFAP2A mAb 3B5 or TFAP2A pAb C-18 or GAPDH pAb V-18 (Santa Cruz Biotechnology, Santa Cruz, CA) or SP1 pAb (Active Motif, Carlsbad, $\mathrm{CA}$ ) or acetylated-H3 histone pAb (Upstate Biotechnology, Lake Placid, NY, U.S.A.). Secondary antibodies used were: goat anti-mouse or anti-rabbit IgG HRP-conjugated, donkey anti-goat IgG HRP-conjugated (Santa Cruz Biotechnology, Santa Cruz, CA); pSP(RSV)TFAP2A and pSP(RSV)-empty expression vectors, a gift from Dr. $\mathrm{H}$. Hurst [73,74] were respectively used to overexpress human TFAP2A in cells and as empty vector control. TFAP2AshRNA2 [39] and pSUPER.retro.puro vector (OligoEngine, Seattle, WA, USA) were respectively used to down-modulate human TFAP2A in cells and as empty vector control.

\section{Molecular cloning of the human Endothelial and Smooth muscle Derived Neuropilin like (DCBLD2/ESDN/CLCP1) promoter}

The upstream regulatory region of the $D C B L D 2 / E S D N /$ CLCP1 (discoidin, CUB and LCCL domain containing 2/ Endothelial and Smooth muscle cell Derived Neuropinlike molecule/CUB, LCCL-homology, coagulation factor V/VIII homology domains protein) gene was identified using the National Center for Biotechnology Information (NCBI) gene bank database (accession number NM_080927). A BAC genomic clone $\underline{\text { RZPDB737B122156D }}$ was purchased from imaGenes (imaGenes GmbH, Berlin, Germany) and a 2274 bps fragment encompassing the putative $D C B L D 2 / E S D N$ promoter region was amplified by PCR, using Takara (Bio Inc., Shiga, Japan) reagents. A final $50 \mu \mathrm{L}$ volume contained: 2.5 U Takara LA Taq enzyme, $1 \times$ PCR Buffer, 400 $\mu \mathrm{M}$ dNTPs, $2.5 \mathrm{mM} \mathrm{MgCl}_{2}, 1 \mu \mathrm{M}$ forward and reverse primers and $0.1 \mu \mathrm{g}$ of DNA. The following primers containing KpnI and BglII restriction sites at the 5 ' ends were used: FW: 5'-GGGGTACCCCCTGGCTGATTGGGGTTTTTA-3'; RV: 5'-GAAGATCTTCGCGGAGCTAAGGAACGTG-3'. A negative control without plasmid was always added. 3'-overhang As were added by a post-incubation with Taq polymerase (Invitrogen Life Technologies, Carlsband, CA) then the fragment was cloned into the $\mathrm{pCR}^{\circ} 2.1$-TOPO vector using the TOPO TA cloning system (Invitrogen Life Technologies, Carlsband, CA). After sequencing, the fragment was excised by KpnI and BglII digestion and subcloned into pGL3Basic Luciferase reporter vector (Promega, Madison, WI) giving rise to the pGL3-ESDN-WT reporter construct (2185 ; +92). A 5'deletion construct was generated by 
digesting pGL3-ESDN-WT vector with KpnI-BalI restriction enzymes, followed by Klenow end-filling reactions (where necessary) and self-recircularization by Invitrogen ligase and named: pGL-ESDN-DEL3 (-950; +92). QuickChange $^{\text {тм }}$ Site-Directed Mutagenesis Kit (Stratagene, La Jolla, CA) was used to generate $7 \mathrm{bp}$-deletions in the central portion of every single TFAP2A binding site in single or multiple combinations and pGL3-ESDN-MUT1, pGL3-ESDN-MUT2, pGL3-ESDN-MUT3, pGL3-ESDNMUT1,2, pGL3-ESDN-MUT1,3, pGL3-ESDN-MUT2,3, pGL3-ESDN-MUT1,2,3 reporter vectors were obtained. Mutagenic primer sequences are listed in Additional file 2 .

\section{Chromatin ImmunoPrecipitation (ChIP) assays}

ChIP was performed using the Magna $\mathrm{ChIP}^{\mathrm{Tm}} \mathrm{G}$ kit (Millipore, Billerica, MA) reagents and protocols. Briefly, chromatin was prepared from HeLa or HepG2 cells at $~ 80-$ $90 \%$. Cells were crosslinked with $1 \%$ formaldehyde (Sigma Aldrich, St Louis, MO) for $10^{\prime}$ at $37^{\circ} \mathrm{C}$. Chromatin shearing was obtained by digesting the DNA with an enzymatic shearing cocktail $(200 \mathrm{U} / \mathrm{ml})$ for $10^{\prime}$ at $37^{\circ} \mathrm{C}$. Chromatin was pre-cleared with Protein $\mathrm{G}$ beads, to reduce non-specific background. Pre-cleared chromatin was immunoprecipitated overnight using $2 \mu \mathrm{g}$ of specific antibodies. In addition, chromatin aliquots were precipitated with either non-specific IgGs or with anti-RNA polymerase II or anti-acetyl-histone H3 antibody, used respectively as negative and positive controls. Immunoprecipitated chromatin was collected by adding protein $G$ beads to the tubes and the beads were washed with ChIPIT $^{\mathrm{Im}}$ Washing Buffers supplemented with protease inhibitors. Immunoprecipitated DNA was collected and after reversing the cross-links, DNA was purified by using the QIAquick PCR Purification Kit mini spin-columns (QIAGEN, Stanford CA), according to manufacturer's instructions. The eluted immunoprecipitated DNA was analyzed by PCR, together with a non-immunoprecipitated chromatin sample (input). Polymerase chain reaction (PCR) was performed using Taq DNA Polymerase (Invitrogen Life Technologies, Carlsband, CA) using $1 \times$ PCR Buffer without $\mathrm{MgCl}_{2}, 0.2 \mathrm{mM}$ dNTPs, $1.5 \mathrm{mM}$ $\mathrm{MgCl}_{2}, 0.5 \mu \mathrm{M}$ forward and reverse primers, $0.625 \mathrm{U}$ Taq DNA Polymerase and $10 \mu \mathrm{L}$ of precipitated DNA. The annealing temperature and the number of cycles were specific for each primer pair. The different primer pairs were designed using the NCBI Primer designing tool and primer sequences as well as PCR experimental conditions are added in Additional file 2. To verify the quality of our ChIP reactions, primers to the GAPDH promoter were used as positive controls.

\section{Transient transfections and luciferase assays}

Twenty-four hours before transfection, HeLa or MDAMB-231 cells were seeded in 24-well plates at $8 \times 10^{4}$ cells per well. Cells were transfected using Lipofectamine 2000 (Invitrogen Life Technologies, Carlsband, CA) and 700 ng of either pGL3-Basic (control) or the various pGL3$D C B L D 2 / E S D N$ promoter fragments generated and mentioned above in presence of 20 ng of pRLTK (Promega, Madison, WI) to normalize for transfection efficiency following the manufacturer's instructions. In co-transfection experiments, $250 \mathrm{ng}$ of $\mathrm{pSP}(\mathrm{RSV}) \mathrm{TFAP} 2 \mathrm{~A}$ or pSP(RSV)NN or TFAP2AshRNA2 or pSUPER.retro.puro vectors were used. Forty-eight hours after transfection cell extracts were prepared by adding $100 \mu \mathrm{l}$ of $1 \times$ Passive Reporter Lysis Buffer (Promega, Madison, WI). The luciferase activities were measured using the Dual Luciferase Assay System (Promega, Madison, WI) according to the manufacturer's instructions. Each transfection was performed in triplicate and repeated three times. For the statistical analysis a student's $t$ test was performed: ${ }^{*} \mathrm{p}_{\mathrm{v}}<0.05 ;{ }^{* *} \mathrm{p}_{\mathrm{v}}<0.01 ;{ }^{* * *} \mathrm{p}_{\mathrm{v}}<0.001$.

\section{Protein preparation and immunoblotting}

Total protein extracts were prepared using a boiling Laemli Buffer containing 0.125 M Tris/ $\mathrm{HCl}, \mathrm{pH} 6.8$ and 2.5\% SDS. $25 \mu \mathrm{g}$ of proteins were separated by $12 \%$ SDS-PAGE and electroblotted onto PVDF membranes (Bio-Rad, Hercules, CA). Membranes were blocked in 5\% non-fat milk-TBS-Tween buffer ( $137 \mathrm{mM} \mathrm{NaCl}, 20 \mathrm{mM}$ Tris/ $\mathrm{HCl}$, $\mathrm{pH} 7.6,0.1 \%$ Tween-20), overnight at $4^{\circ} \mathrm{C}$, then incubated with appropriate antibodies for 1 hour at room temperature and visualized by enhanced chemiluminescence (ECL ${ }^{\circ}$, Amersham Biosciences, Pisactaway, NJ).

\section{Ingenuity Pathway Analysis Systems}

The Ingenuity Pathways Knowledge Base http:// www.ingenuity.com is currently the world's largest database of knowledge on biological networks, with annotations organized by experts. We exploited this database to define the presence of functional associations within the genes detected by microarray analysis, to identify enriched ontological gene classes and to draw simplified network connections among genes. Each network was ranked based on "scores" which consider how relevant the networks are to the genes in our input dataset. Each score is based on a p-value calculation, which takes in account the probability that the genes present in a network are found in it just by chance. Mathematically, the score is simply the negative exponent of the right-tailed Fisher's exact test result.

\section{Additional material}

Additional file 1 Microarray analysis (Whole Human Genome Agilent $44 \mathrm{~K}$ ) was performed on HeLa cells transiently transfected with either generic non-silencing (NS) or specific TFAP2A (oligo TFAP2A) siRNA oligos. The accession numbers of 494 modulated gene [39] were unambig uously converted to ENSEMBL IDs (version 46) and used for our analysis as listed here. 


\section{Additional file $\mathbf{2}$ List of primers and PCR conditions used for cloning,} mutagenesis and ChIP assays.

\section{Abbreviations}

TFs: transcription factors; PWM: Positional Weight Matrix; ChIP: Chromatin ImmunoPrecipitation; TFBSs: TF Binding Sites; PFM: Positional Frequency Matrix; TSS: Transcriptional Start Site; GO: Gene Ontology; FC: Fold Change.

\section{Authors' contributions}

FO participated in the design and coordination of the study, performed the ChIP-analyses and drafted the manuscript. DC participated in the design and coordination of the study and performed bioinformatics analyses. BU performed the ChIP and ESDN-promoter analyses and participated in writing the manuscript. PP supervised the bioinformatics analyses. MC supervised the bioinformatics analyses, interpreted the bioinformatics results and contributed to the organization of the manuscript. DT participated in the design and coordination of the study, interpreted the results, drafted the manuscript and supervised the revision. All authors read and approved the final manuscript.

\section{Acknowledgements}

This work was supported by grants from the University of Torino (Local Research Funding 2007/DT, 2008/DT), Regione Piemonte Ricerca Scientifica Applicata (CIPE2004/DT) and by Fund for Investments of Basic Research (FIRB) from the Italian Ministry of the University and Scientific Research, No. RBNE03B8KK-006/MC. FO and DC are fellows of the Regione Piemonte. We thank Dr. H. Hurst for providing the pSP(RSV)NN and pSP(RSV)TFAP2A vectors and Valeria Poli for critical reading of the manuscript.

\section{Author Details}

${ }^{1}$ Molecular Biotechnology Center (MBC) and Department of Oncological Sciences, University of Torino, Via Nizza, 52, 10126 Torino, Italy, ${ }^{2}$ National Institute of Nuclear Physics (INFN) and Department of Theoretical Physics, University of Torino, Via Pietro Giuria, 1, 10125, Torino, Italy, ${ }^{3}$ Molecular Biotechnology Center (MBC) and Department of Genetics, Biology and Biochemistry, University of Torino, Via Nizza, 52, 10126 Torino, Italy, ${ }^{4}$ Center for Complex Systems in Molecular Biology and Medicine, University of Torino, Via Acc. Albertina, 13, 10023 Torino; Italy, 5Systems Biology Lab, Institute for Cancer Research and Treatment (IRCC), School of Medicine, University of Torino, Str Prov. 142 Km. 3.95, I-10060 Candiolo, Torino, Italy and ${ }^{6}$ Cancer Research UK London Research Institute, Lincoln's Inn Fields Laboratories, Vascular Biology Laboratory, 44 Lincoln's Inn Fields, London, WC2A 3PX, UK

Received: 1 March 2010 Accepted: 3 June 2010

Published: 3 June 2010

\section{References}

1. Wasserman WW, Sandelin A: Applied bioinformatics for the identification of regulatory elements. Nat Rev Genet 2004, 5(4):276-287.

2. Boyer LA, Lee TI, Cole MF, Johnstone SE, Levine SS, Zucker JP, Guenther MG, Kumar RM, Murray HL, Jenner RG, et al:: Core transcriptional regulatory circuitry in human embryonic stem cells. Cell 2005, 122(6):947-956

3. Bouvet $P$ : Identification of nucleic acid high-affinity binding sequences of proteins by SELEX. Methods Mol Biol 2009, 543:139-150.

4. Pollock J, Baule VJ, Rich CB, Ginsburg CD, Curtiss SW, Foster JA: Chick tropoelastin isoforms. From the gene to the extracellular matrix. J Biol Chem 1990, 265(7):3697-3702.

5. Chang LW, Nagarajan R, Magee JA, Milbrandt J, Stormo GD: A systematic model to predict transcriptional regulatory mechanisms based on overrepresentation of transcription factor binding profiles. Genome Res 2006, 16(3):405-413.

6. Ostrin EJ, Li Y, Hoffman K, Liu J, Wang K, Zhang L, Mardon G, Chen R: Genome-wide identification of direct targets of the Drosophila retinal determination protein Eyeless. Genome research 2006, 16(4):466-476.

7. Scharer CD, McCabe CD, Ali-Seyed M, Berger MF, Bulyk ML, Moreno CS: Genome-wide promoter analysis of the SOX4 transcriptional network in prostate cancer cells. Cancer research 2009, 69(2):709-717.

8. Cheng C, Ying K, Xu M, Zhao W, Zhou Z, Huang Y, Wang W, Xu J, Zeng L, $X i e Y$, et al:: Cloning and characterization of a novel human transcription factor AP-2 beta like gene (TFAP2BL1). The international journal of biochemistry \& cell biology 2002, 34(1):78-86.
9. Zhao F, Satoda M, Licht JD, Hayashizaki Y, Gelb BD: Cloning and characterization of a novel mouse AP-2 transcription factor, AP-2delta, with unique DNA binding and transactivation properties. $\mathrm{J} \mathrm{Bio} / \mathrm{Chem}$ 2001, 276(44):40755-40760.

10. Feng W, Williams T: Cloning and characterization of the mouse AP-2 epsilon gene: a novel family member expressed in the developing olfactory bulb. Molecular and cellular neurosciences 2003, 24(2):460-475

11. Wang HV, Vaupel $K$, Buettner R, Bosserhoff AK, Moser M: Identification and embryonic expression of a new AP-2 transcription factor, AP-2 epsilon. Dev Dyn 2004, 231(1):128-135.

12. Hilger-Eversheim $K$, Moser M, Schorle H, Buettner R: Regulatory roles of AP-2 transcription factors in vertebrate development, apoptosis and cell-cycle control. Gene 2000, 260(1-2):1-12.

13. Werling $U$, Schorle $H$ : Transcription factor gene AP-2 gamma essential for early murine development. Mol Cell Biol 2002, 22(9):3149-3156.

14. Eckert D, Buhl S, Weber S, Jager R, Schorle H: The AP-2 family of transcription factors. Genome biology 2005, 6(13):246.

15. Williams T, Tjian R: Characterization of a dimerization motif in AP-2 and its function in heterologous DNA-binding proteins. Science New York, NY 1991, 251(4997):1067-1071.

16. Mohibullah N, Donner A, Ippolito JA, Williams T: SELEX and missing phosphate contact analyses reveal flexibility within the AP-2[alpha] protein: DNA binding complex. Nucleic acids research 1999, 27(13):2760-2769.

17. Gaynor RB, Muchardt C, Xia YR, Klisak I, Mohandas T, Sparkes RS, Lusis AJ: Localization of the gene for the DNA-binding protein AP-2 to human chromosome 6p22.3-pter. Genomics 1991, 10(4):1100-1102.

18. Gee MS, Sarkisian CJ, el-Deiry WS: Identification of a novel AP-2 consensus DNA binding site. Biochemical and biophysical research communications 1998, 243(1):307-316.

19. Stormo GD: DNA binding sites: representation and discovery. Bioinformatics, Oxford, England 2000, 16(1):16-23.

20. McPherson LA, Weigel RJ: AP2alpha and AP2gamma: a comparison of binding site specificity and trans-activation of the estrogen receptor promoter and single site promoter constructs. Nucleic acids research 1999, 27(20):4040-4049.

21. Wu F, Lee AS: YY1 as a regulator of replication-dependent hamster histone H3.2 promoter and an interactive partner of AP-2. J Biol Chem 2001, 276(1):28-34.

22. Mertens PR, Alfonso-Jaume MA, Steinmann K, Lovett DH: A synergistic interaction of transcription factors $A P 2$ and $Y B-1$ regulates gelatinase $A$ enhancer-dependent transcription. J Biol Chem 1998, 273(49):32957-32965.

23. McPherson LA, Loktev AV, Weigel RJ: Tumor suppressor activity of AP2alpha mediated through a direct interaction with p53. J Biol Chem 2002, 277(47):45028-45033.

24. Pena P, Reutens AT, Albanese C, D'Amico M, Watanabe G, Donner A, Shu IW, Williams T, Pestell RG: Activator protein-2 mediates transcriptional activation of the CYP11A1 gene by interaction with Sp1 rather than binding to DNA. Molecular endocrinology, Baltimore, Md 1999, 13(8):1402-1416.

25. Batsche E, Muchardt C, Behrens J, Hurst HC, Cremisi C: RB and c-Myc activate expression of the E-cadherin gene in epithelial cells through interaction with transcription factor AP-2. Mol Cell Bio/ 1998, 18(7):3647-3658.

26. Sivak JM, West-Mays JA, Yee A, Williams T, Fini ME: Transcription Factors Pax6 and AP-2alpha Interact To Coordinate Corneal Epithelial Repair by Controlling Expression of Matrix Metalloproteinase Gelatinase B. $\mathrm{Mol}$ Cell Biol 2004, 24(1):245-257

27. Wu F, Lee AS: CDP and AP-2 mediated repression mechanism of the replication-dependent hamster histone H3.2 promoter. Journal of cellular biochemistry 2002, 84(4):699-707.

28. Mori N, Prager D: High levels of AP-2-binding activity in cell lines infected with human T-cell leukemia virus type I: possible enhancement of AP-2 binding by human T-cell leukemia virus type I tax. Cancer research 1996, 56(4):779-782.

29. Somasundaram K, Jayaraman G, Williams T, Moran E, Frisch S, Thimmapaya B: Repression of a matrix metalloprotease gene by E1A correlates with its ability to bind to cell type-specific transcription factor AP-2. Proceedings of the National Academy of Sciences of the United States of America 1996, 93(7):3088-3093. 
30. Aqeilan RI, Palamarchuk A, Weigel RJ, Herrero JJ, Pekarsky Y, Croce CM: Physical and functional interactions between the Wwox tumor suppressor protein and the AP-2gamma transcription factor. Cancer research 2004, 64(22):8256-8261.

31. Ding X, Fan C, Zhou J, Zhong Y, Liu R, Ren K, Hu X, Luo C, Xiao S, Wang Y, et al: GAS41 interacts with transcription factor AP-2beta and stimulates AP-2beta-mediated transactivation. Nucleic acids research 2006, 34(9):2570-2578.

32. Kannan P, Yu Y, Wankhade S, Tainsky MA: PolyADP-ribose polymerase is a coactivator for AP-2-mediated transcriptional activation. Nucleic acids research 1999, 27(3):866-874.

33. Li Q, Dashwood RH: Activator protein 2alpha associates with adenomatous polyposis coli/beta-catenin and Inhibits beta-catenin/Tcell factor transcriptional activity in colorectal cancer cells. J Biol Chem 2004, 279(44):45669-45675.

34. Braganca J, Eloranta JJ, Bamforth SD, Ibbitt JC, Hurst HC, Bhattacharya S: Physical and functional interactions among AP-2 transcription factors, p300/CREB-binding protein, and CITED2. J Biol Chem 2003, 278(18):16021-16029.

35. Braganca J, Swingler T, Marques FI, Jones T, Eloranta JJ, Hurst HC, Shioda T, Bhattacharya S: Human CREB-binding protein/p300-interacting transactivator with ED-rich tail (CITED) 4, a new member of the CITED family, functions as a co-activator for transcription factor AP-2. J Biol Chem 2002, 277(10):8559-8565.

36. Kannan P, Tainsky MA: Coactivator PC4 mediates AP-2 transcriptional activity and suppresses ras-induced transformation dependent on AP2 transcriptional interference. Mol Cell Biol 1999, 19(1):899-908.

37. Campillos M, Garcia MA, Valdivieso F, Vazquez J: Transcriptional activation by AP-2alpha is modulated by the oncogene DEK. Nucleic acids research 2003, 31(5):1571-1575.

38. Yagi R, Chen LF, Shigesada K, Murakami Y, Ito Y: A WW domaincontaining yes-associated protein (YAP) is a novel transcriptional coactivator. The EMBO journal 1999, 18(9):2551-2562.

39. Orso F, Penna E, Cimino D, Astanina E, Maione F, Valdembri D, Giraudo E, Serini G, Sismondi P, De Bortoli M, et al:: AP-2alpha and AP-2gamma regulate tumor progression via specific genetic programs. FASEB J 2008, 22(8):2702-2714.

40. Wang T, Stormo GD: Combining phylogenetic data with co-regulated genes to identify regulatory motifs. Bioinformatics, Oxford, England 2003, 19(18):2369-2380.

41. Cora D, Di Cunto F, Caselle M, Provero P: Identification of candidate regulatory sequences in mammalian 3' UTRs by statistical analysis of oligonucleotide distributions. BMC Bioinformatics 2007, 8:174.

42. Xie X, Lu J, Kulbokas EJ, Golub TR, Mootha V, Lindblad-Toh K, Lander ES, Kellis M: Systematic discovery of regulatory motifs in human promoters and 3' UTRs by comparison of several mammals. Nature 2005, 434(7031):338-345.

43. Ho Sui SJ, Mortimer JR, Arenillas DJ, Brumm J, Walsh CJ, Kennedy BP Wasserman WW: oPOSSUM: identification of over-represented transcription factor binding sites in co-expressed genes. Nucleic acids research 2005, 33(10):3154-3164.

44. Bailey $T L$, Elkan C: Fitting a mixture model by expectation maximization to discover motifs in biopolymers. Proc Int Conf Intell Syst Mol Biol 1994, 2:28-36.

45. Jolly ER, Chin CS, Herskowitz I, Li H: Genome-wide identification of the regulatory targets of a transcription factor using biochemical characterization and computational genomic analysis. BMC Bioinformatics 2005, 6:275.

46. Orso F, Jager R, Calogero RA, Schorle H, Sismondi P, De Bortoli M, Taverna D: AP-2alpha regulates migration of $\mathrm{GN}-11$ neurons via a specific genetic programme involving the $\mathrm{Axl}$ receptor tyrosine kinase. BMC Biol 2009, 7:25.

47. Ruiz M, Pettaway C, Song R, Stoeltzing O, Ellis L, Bar-Eli M: Activator protein 2alpha inhibits tumorigenicity and represses vascular endothelial growth factor transcription in prostate cancer cells. Cancer Res 2004, 64(2):631-638.

48. Brose K, Tessier-Lavigne M: Slit proteins: key regulators of axon guidance, axonal branching, and cell migration. Curr Opin Neurobiol 2000, 10(1):95-102.

49. Millette E, Rauch BH, Kenagy RD, Daum G, Clowes AW: Platelet-derived growth factor-BB transactivates the fibroblast growth factor receptor to induce proliferation in human smooth muscle cells. Trends Cardiovasc Med 2006, 16(1):25-28.

50. Cha BY, Shi WL, Yonezawa T, Teruya T, Nagai K, Woo JT: An inhibitory effect of chrysoeriol on platelet-derived growth factor (PDGF)-induced proliferation and PDGF receptor signaling in human aortic smooth muscle cells. J Pharmacol Sci 2009, 110(1):105-110.

51. Yamazaki D, Kurisu S, Takenawa T: Regulation of cancer cell motility through actin reorganization. Cancer Sci 2005, 96(7):379-386.

52. Monypenny J, Zicha D, Higashida C, Oceguera-Yanez F, Narumiya S, Watanabe N: Cdc42 and Rac family GTPases regulate mode and speed but not direction of primary fibroblast migration during PDGFdependent chemotaxis. Mol Cell Biol 2009

53. Cho MC, Lee K, Paik SG, Yoon DY: Peroxisome Proliferators-Activated Receptor (PPAR) Modulators and Metabolic Disorders. PPAR Res 2008 2008:679137.

54. Boutros T, Chevet E, Metrakos P: Mitogen-activated protein (MAP) kinase/MAP kinase phosphatase regulation: roles in cell growth, death, and cancer. Pharmacol Rev 2008, 60(3):261-310.

55. Salanga $C L$, O'Hayre M, Handel T: Modulation of chemokine receptor activity through dimerization and crosstalk. Cell Mol Life Sci 2009, 66(8):1370-1386.

56. Dhawan $P$, Richmond $A$ : Role of $C X C L 1$ in tumorigenesis of melanoma. Journal of leukocyte biology 2002, 72(1):9-18.

57. Mochizuki S, Okada Y: ADAMs in cancer cell proliferation and progression. Cancer Sci 2007, 98(5):621-628.

58. Gschwind A, Hart S, Fischer OM, Ullrich A: TACE cleavage of proamphiregulin regulates GPCR-induced proliferation and motility of cancer cells. The EMBO journal 2003, 22(10):2411-2421.

59. Yin T, Yang YC: Mitogen-activated protein kinases and ribosomal S6 protein kinases are involved in signaling pathways shared by interleukin-11, interleukin-6, leukemia inhibitory factor, and oncostatin M in mouse 3T3-L1 cells. J Biol Chem 1994, 269(5):3731-3738.

60. Mitchell DC, Abdelrahim M, Weng J, Stafford LJ, Safe S, Bar-Eli M, Liu M: Regulation of KiSS-1 metastasis suppressor gene expression in breast cancer cells by direct interaction of transcription factors activator protein-2alpha and specificity protein-1. J Biol Chem 2006, 281(1):51-58.

61. Liu R, Zhou A, Ren D, He A, Hu X, Zhang W, Yang L, Liu M, Li H, Zhou J, et al:: Transcription factor specificity protein 1 (SP1) and activating protein 2alpha (AP-2alpha) regulate expression of human KCTD10 gene by binding to proximal region of promoter. The FEBS journal 2009, 276(4):1114-1124.

62. Koshikawa K, Osada H, Kozaki K, Konishi H, Masuda A, Tatematsu Y, Mitsudomi T, Nakao A, Takahashi T: Significant up-regulation of a novel gene, CLCP1, in a highly metastatic lung cancer subline as well as in lung cancers in vivo. Oncogene 2002, 21(18):2822-2828.

63. Nagai $H$, Sugito N, Matsubara $H$, Tatematsu $Y$, Hida T, Sekido $Y$, Nagino M, Nimura $Y$, Takahashi T, Osada H: CLCP1 interacts with semaphorin 4B and regulates motility of lung cancer cells. Oncogene 2007, 26(27):4025-4031

64. Kim M, Lee KT, Jang HR, Kim JH, Noh SM, Song KS, Cho JS, Jeong HY, Kim SY, Yoo HS, et al:: Epigenetic down-regulation and suppressive role of DCBLD2 in gastric cancer cell proliferation and invasion. Mol Cancer Res 2008, 6(2):222-230.

65. Minn AJ, Gupta GP, Siegel PM, Bos PD, Shu W, Giri DD, Viale A, Olshen AB, Gerald WL, Massague J: Genes that mediate breast cancer metastasis to lung. Nature 2005, 436(7050):518-524

66. Chang HY, Sneddon JB, Alizadeh AA, Sood R, West RB, Montgomery K, Chi $J$, van de Rijn $M$, Botstein D, Brown PO: Gene expression signature of fibroblast serum response predicts human cancer progression: similarities between tumors and wounds. PLoS biology 2004, 2(2):E7.

67. Hubbard TJ, Aken BL, Beal K, Ballester B, Caccamo M, Chen Y, Clarke L, Coates G, Cunningham F, Cutts T, et al.: Ensembl 2007. Nucleic acids research 2007:D610-617.

68. Re A, Cora D, Taverna D, Caselle M: Genome-wide survey of microRNAtranscription factor feed-forward regulatory circuits in human. $\mathrm{Mol}$ Biosyst 2009, 5(8):854-867.

69. Vallania F, Schiavone D, Dewilde S, Pupo E, Garbay S, Calogero R, Pontoglio M, Provero P, Poli V: Genome-wide discovery of functional transcription factor binding sites by comparative genomics: the case of Stat3. Proceedings of the National Academy of Sciences of the United States of America 2009, 106(13):5117-5122. 
70. van Helden J, Andre B, Collado-Vides J: Extracting regulatory sites from the upstream region of yeast genes by computational analysis of oligonucleotide frequencies. Journal of molecular biology 1998, 281(5):827-842.

71. Benjamini Y, Drai D, Elmer G, Kafkafi N, Golani I: Controlling the false discovery rate in behavior genetics research. Behav Brain Res 2001, 125(1-2):279-284

72. Cora D, Herrmann C, Dieterich C, Di Cunto F, Provero P, Caselle M: Ab initio identification of putative human transcription factor binding sites by comparative genomics. BMC Bioinformatics 2005, 6:110.

73. Bosher JM, Totty NF, Hsuan JJ, Williams T, Hurst HC: A family of AP-2 proteins regulates $\mathrm{c}$-erbB-2 expression in mammary carcinoma. Oncogene 1996, 13(8):1701-1707.

74. Bosher JM, Williams T, Hurst HC: The developmentally regulated transcription factor AP-2 is involved in c-erbB-2 overexpression in human mammary carcinoma. Proceedings of the National Academy of Sciences of the United States of America 1995, 92(3):744-747.

doi: 10.1186/1471-2164-11-355

Cite this article as: Orso et al., Identification of functional TFAP2A and SP1 binding sites in new TFAP2A-modulated genes BMC Genomics 2010, 11:355

Submit your next manuscript to BioMed Central and take full advantage of:

- Convenient online submission

- Thorough peer review

- No space constraints or color figure charges

- Immediate publication on acceptance

- Inclusion in PubMed, CAS, Scopus and Google Scholar

- Research which is freely available for redistribution

Submit your manuscript at www.biomedcentral.com/submit
C) Biomed Central 